\title{
الأبعاد التنموية لتدريب المعلمين على التعليم في مجال التغير المناخى في إطار المدرسة الشاملة لمواجهة تحديات القرن الحادى والعثرين
}

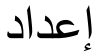

أ.د. تقيده سيد أحمد غانم 1

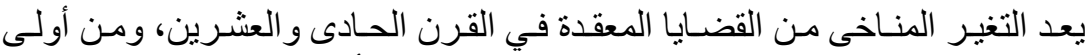

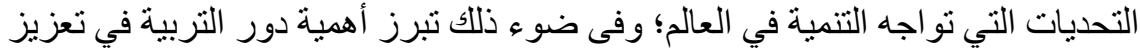

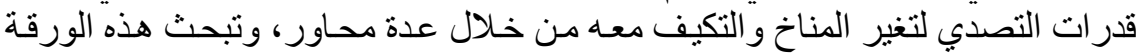

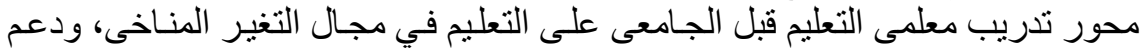

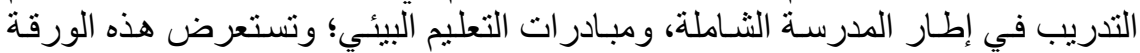

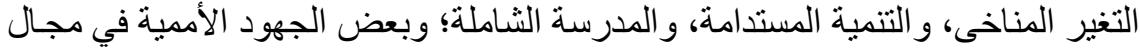

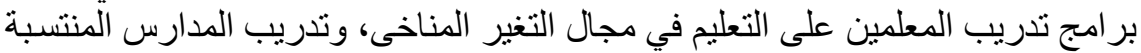

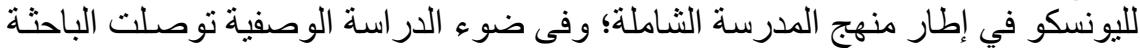

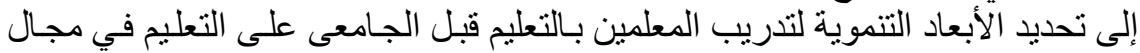

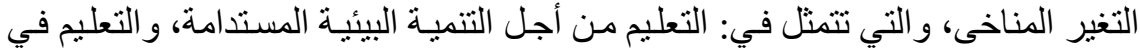

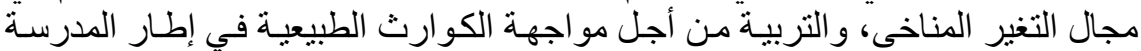

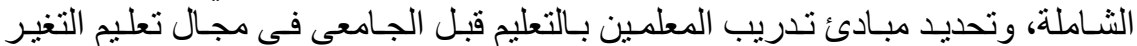

الكلمات المفتاحية: التعليم في مجال التغير المناخى ـ المدرسة الثاملة - الأبعاد

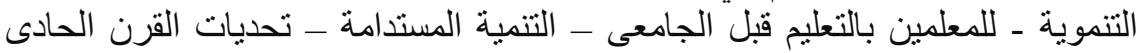
و العشرين.

1 أستاذ باحث، شعبة بحوث تطوير المناهج، المركز القومى للبحوث التربوية والتنمية، القاهرة. drtafida_ncerd@yahoo.com 
المجلة المصرية للتربية العلمية المجلد الثالث والعشرون العدد السادس أكتوبر 2020م

\title{
Developmental dimensions of teachers training on education in the field of climate change within the framework of the comprehensive school to meet the challenges of the twenty-first century
}

\section{Prof. Tafida Sayed Ahmed Ghanem²}

\begin{abstract}
Climate change is considered one of the complex issues in the twenty-first century. Though, the importance of enhancing the role of education in climate change's mitigation and adaptation capabilities emerges through several axes. This paper discusses teachers training in pre-university education of education for climate change, and support teacher's training within the framework of comprehensive school, and environmental education initiatives. This paper reviews climate change, sustainable development, some international efforts in the field of teacher training programs on climate change education, and training schools affiliated with UNESCO within the framework of the comprehensive school curriculum. Finally, in light of the descriptive study, the researcher reaches to determine the developmental dimensions for training pre-university education teachers on climate change education, which are education for sustainable environmental development, and teaching climate change, and disasters education in comprehensive school framework. Moreover, define the principles for training preuniversity education teachers on climate change education.
\end{abstract}

Key words: climate change education - comprehensive school developmental dimensions - pre-university education teachers sustainable development - challenges of the twenty-first century.

${ }^{2}$ Research Professor - Curricula Development Research Department National Center for Educational Research and Development (NCERD) Cairo, Egypt-drtafida_ncerd@yahoo.com 
يعد تغير المناخ من أبرز الأحداث المتوقع تأثير ها في حياة الإنسان في العصر الكير

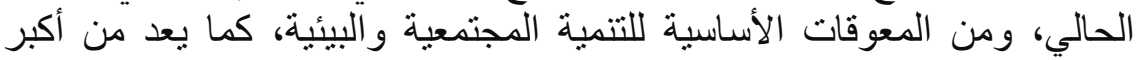
التهديدات للاقتصاد العالمي في القرن الحادي والات العشرين.

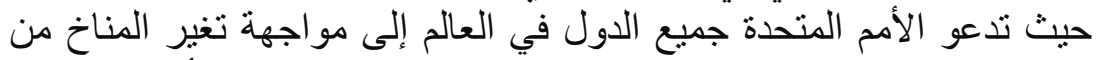

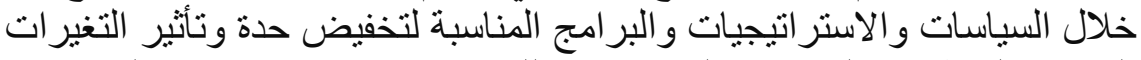

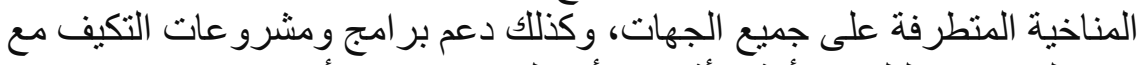

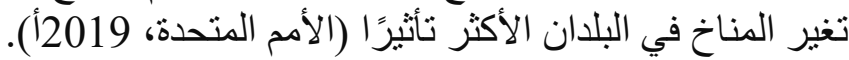

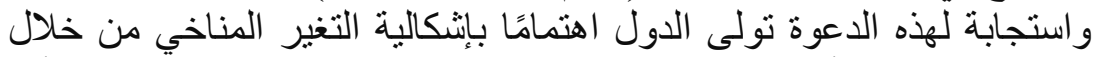

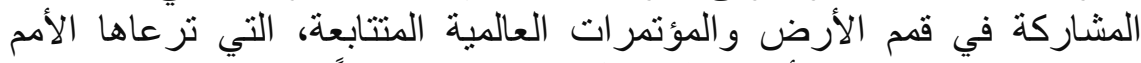

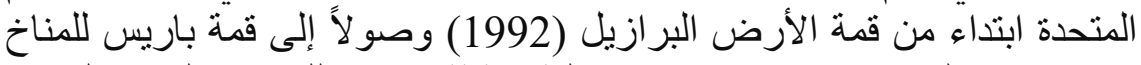

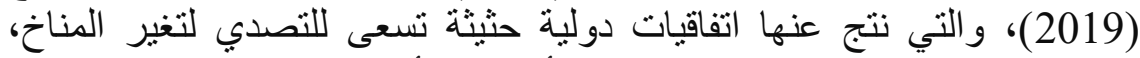

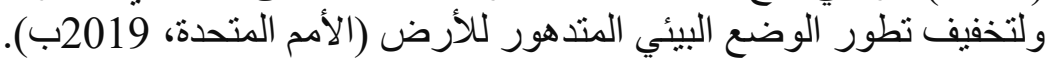

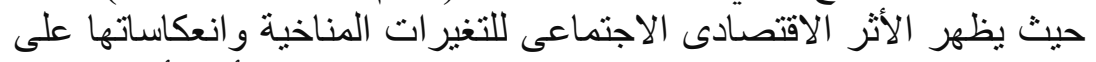

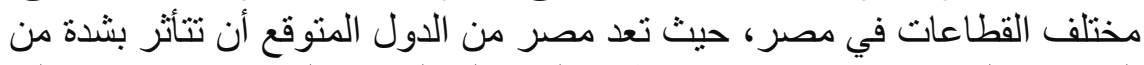

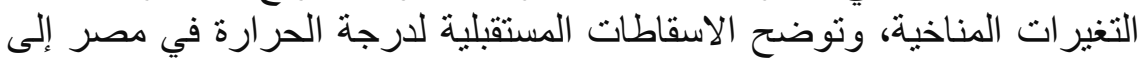

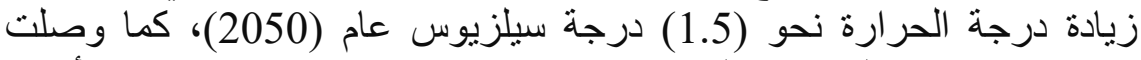

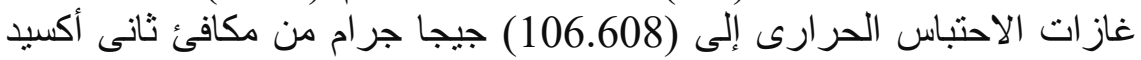

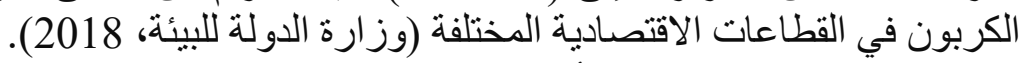

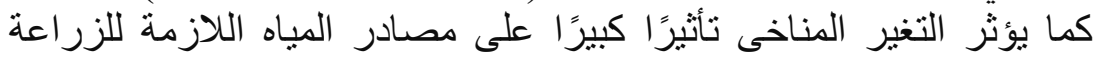

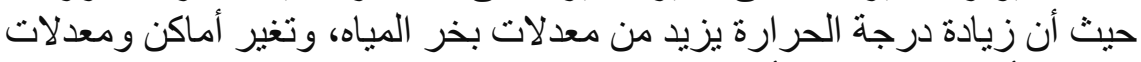

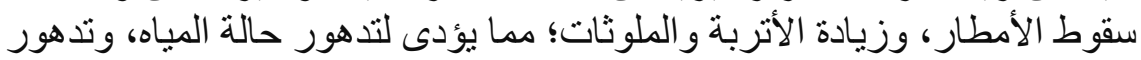

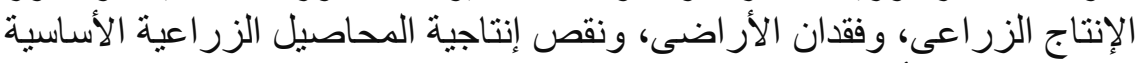

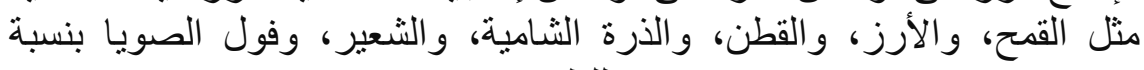

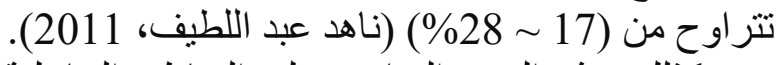

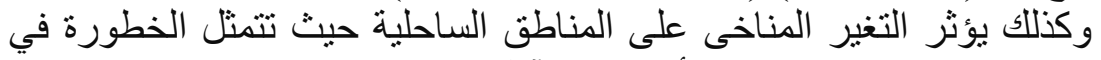

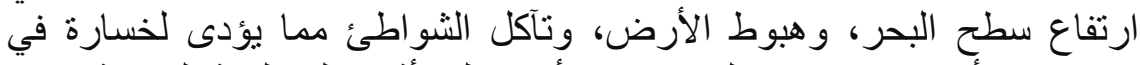

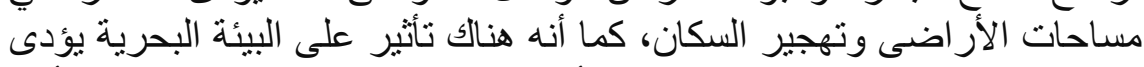

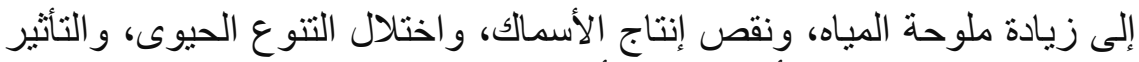

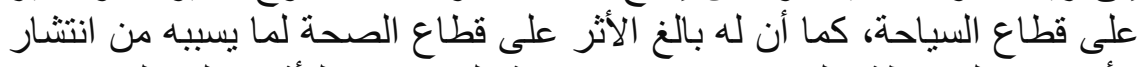

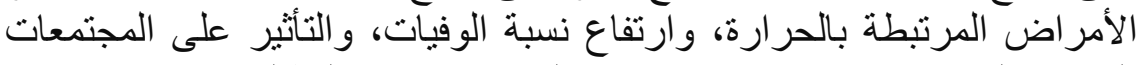

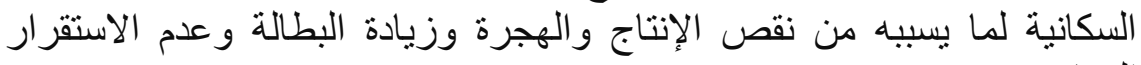

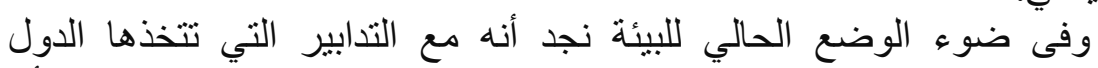

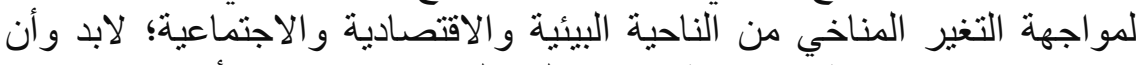
يوازيها تدابير تربوية وتوعوية تهذف إلى السعي لاكتساب الأفراد في جميع الأيع 
المراحل التعليمية المفاهيم والاتجاهات بالتصدي لتغير المناخ و التكيف معنها،

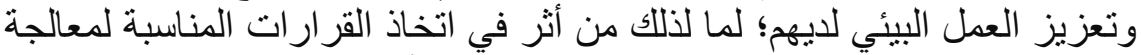

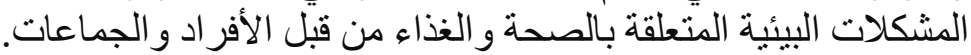

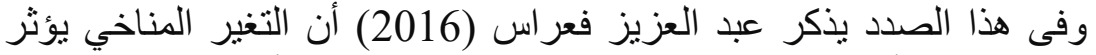

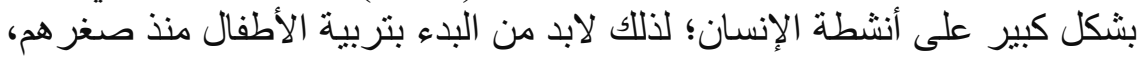

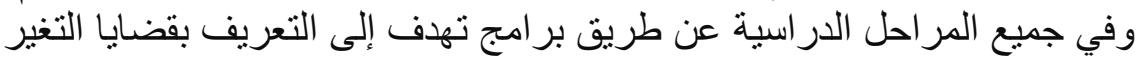

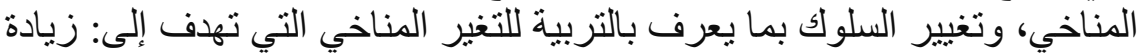

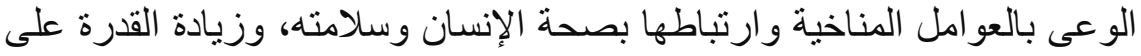

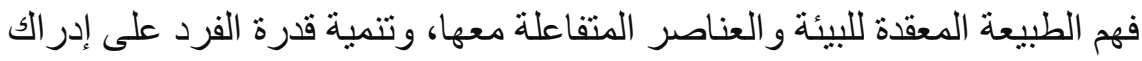

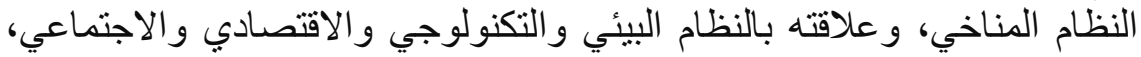

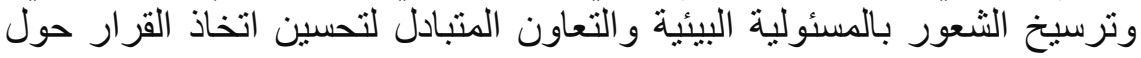

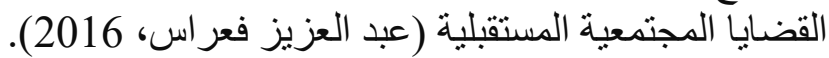

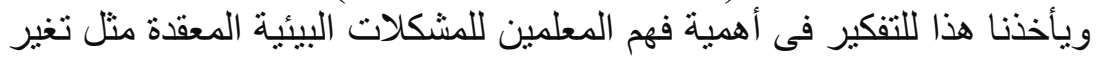

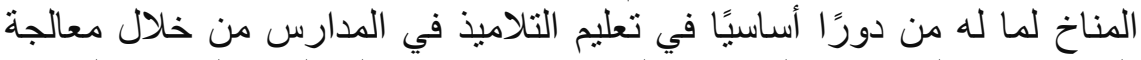

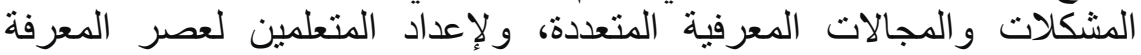
. (2015 Khan,) حيث تقر منظمة الأمم المتحدة للتربية والعلوم و الثقافة (يونسكو) بأن تعزيز

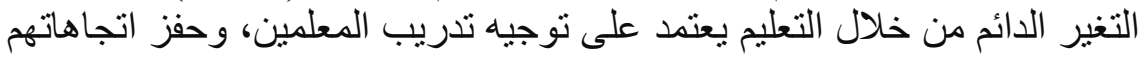

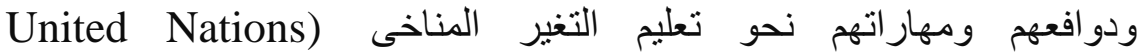

.(Educational, Scientific, and Cultural Organization, 2010

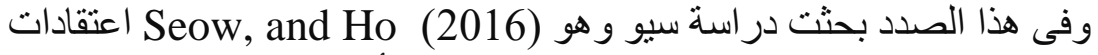

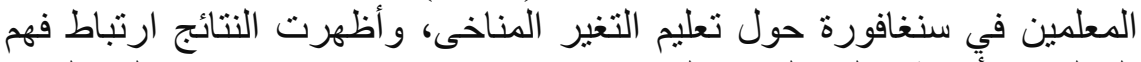

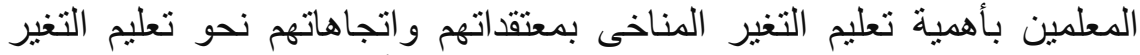

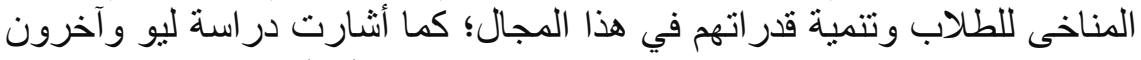
عiu et al. (2015) للقضايا البيئية. ولكن تثير نتائج بعض الدر اسات أنهاته هنالك شكوك حول حالة التعليم في مجال

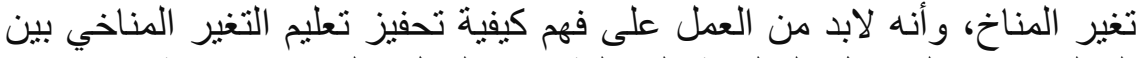

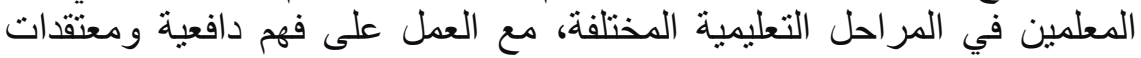

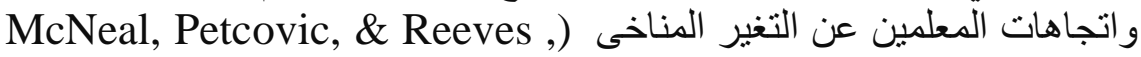
. (2017

فعند النظر إلى حالة المعلمين فيما يتعلق بالتعليم في مجال التغير المناخى على التى التي

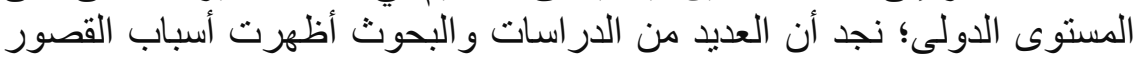

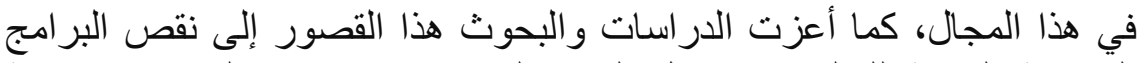

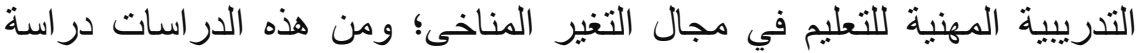

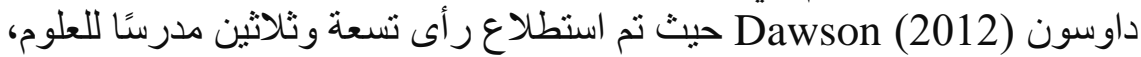

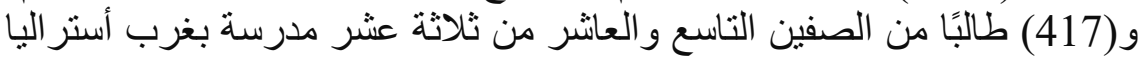


حول وجهات نظرهم حول أهمية علوم تغير المناخ. حيث أجاب المعلمون

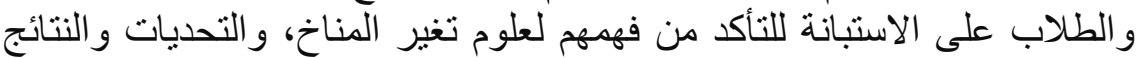

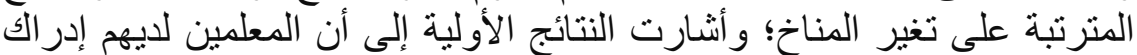

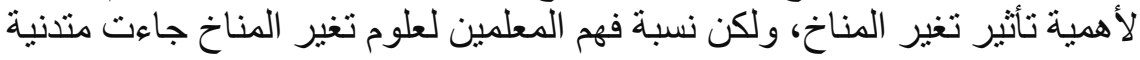
مما انعكس على نتائج طلابهم.

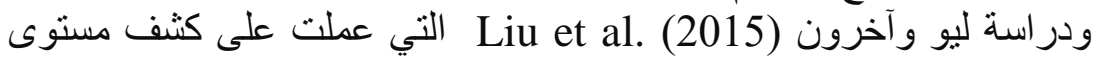
فهم معلمى العلوم في الخدمة لقضايا التغير المناخى، وعلئ وعلاقته بتدريسهم لقضايا

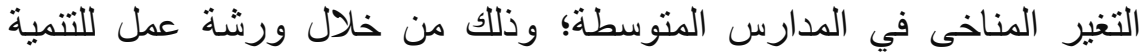

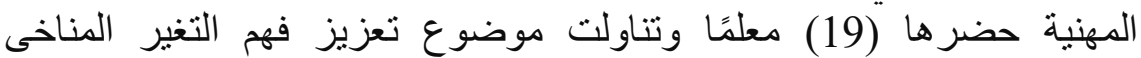

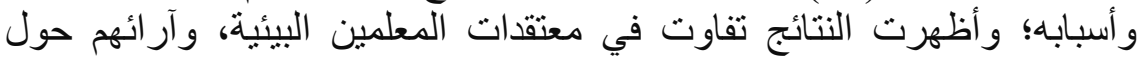

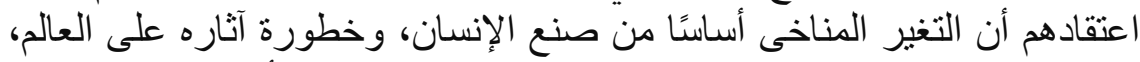

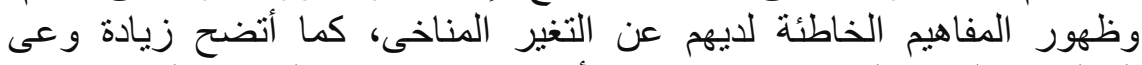

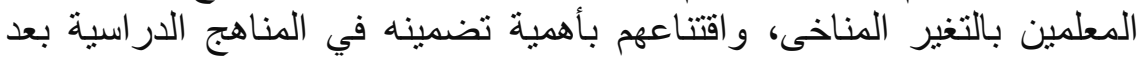
حضور ورشة العمل المهنية عن التغير المناخى.

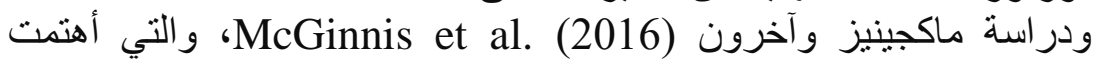

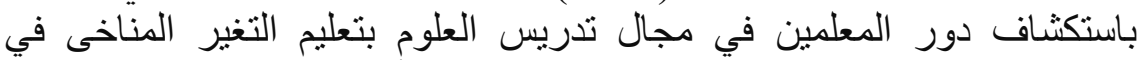

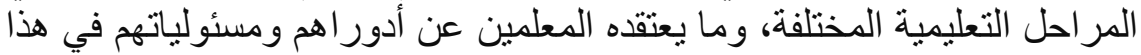

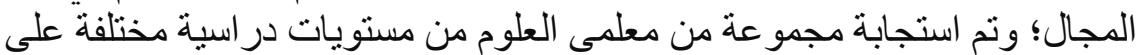

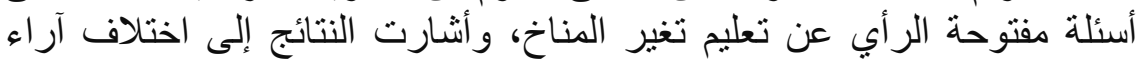

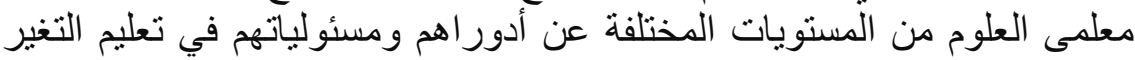

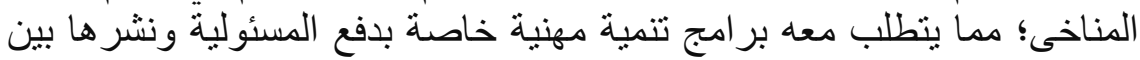

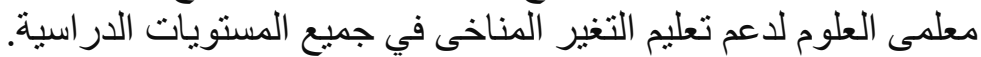

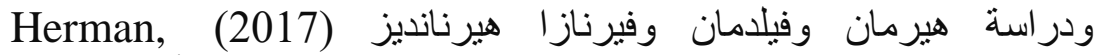
Feldman, and Vernaza-Hernandez, الخاطئة على فهم التغير المناخى، واتجاهات معلمى العلوم في المدارس المتوسطة

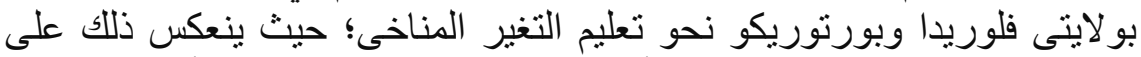

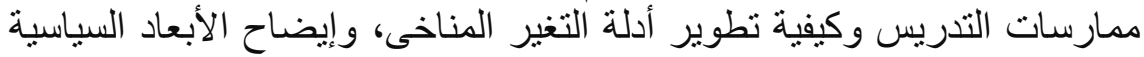
و الاجتماعية والاقتصادية لتورينة لتغير المناخ.

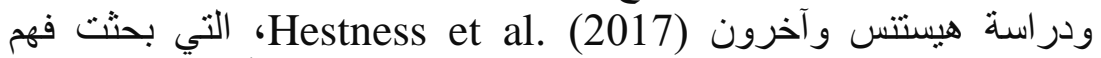

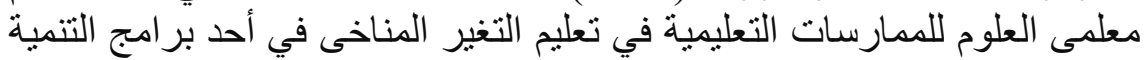

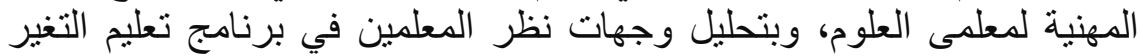

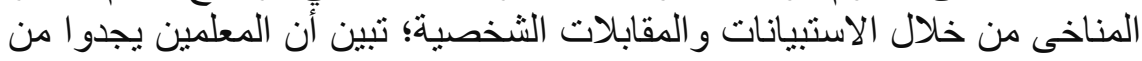

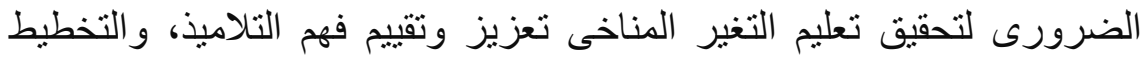

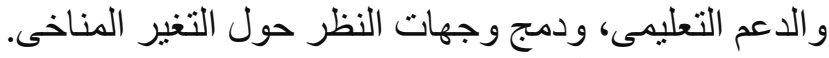

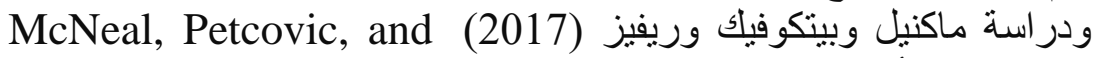
Reeves

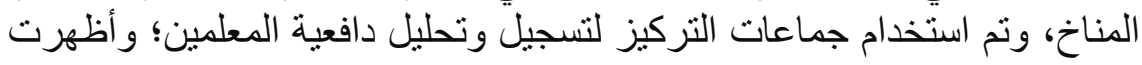


النتائج عن دافعية المعلمين لتدريس التغير المناخى، وأن لدى المعلمين اهتمام

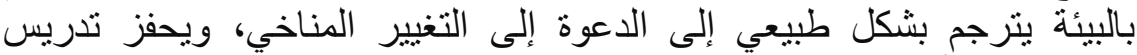
الموضوع؛ وأن المعلمين ذوى المعرفة و الخبرة لديهم ثقة بتدريس التئ التغير المناخى

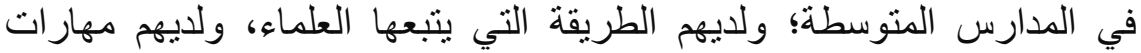

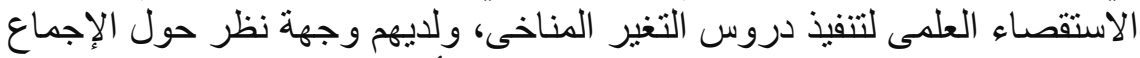

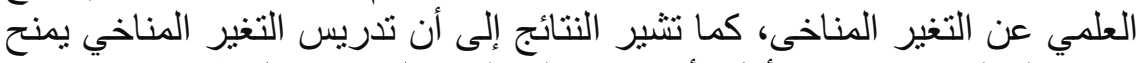

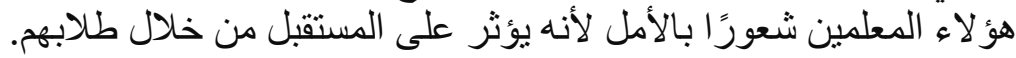

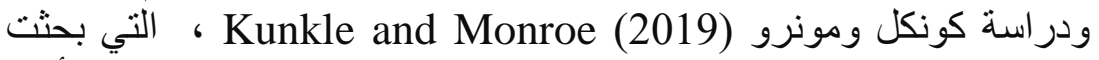
استعداد معلمى العلوم لدعم تدريس التغير المناخى؛ وقام الباحثان بمسح أراء معلىى العلوم في جنوب شرق الولايات المتحدة الأمريكية باستخدام الانترنت،

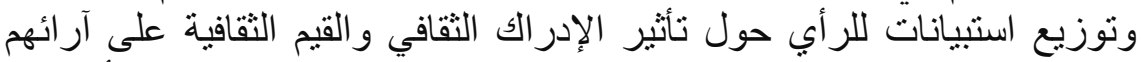

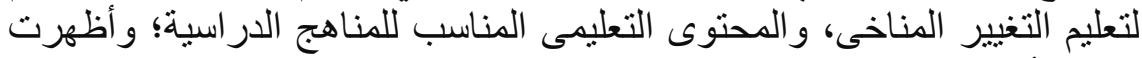

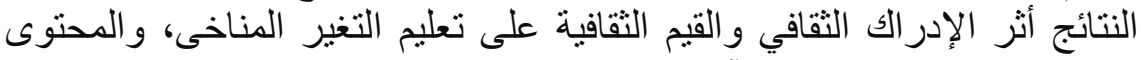
التعليمى للمناهج الدر اسية، و آر اء المعلمين في دعم تعليم تغير المناخ نظرًا لظهور

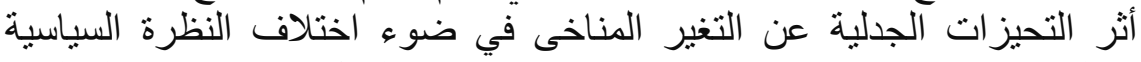

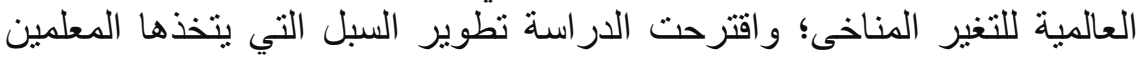

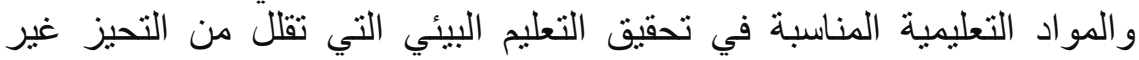
المقصود للمعلمين بسبب القيم التقافية ضد تعليم التغير المناخى، والعمل على لعى زيادة دعم المعلمين لتدريس التغير المناخى وأسبابه و الحلول المحتملة لعلاج آثاره بغض النظر عن التحيز ات الجدلية و الثقافية.

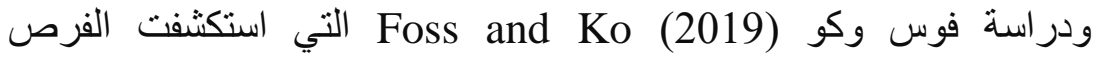
والمعوقات التي تعترض معلمى العلوم في نشر تعليم التغير المناخى في ولاية

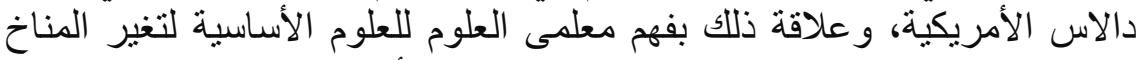

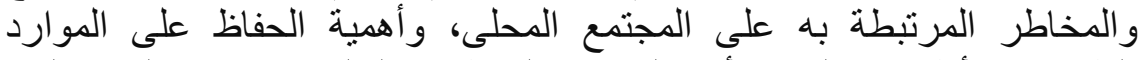

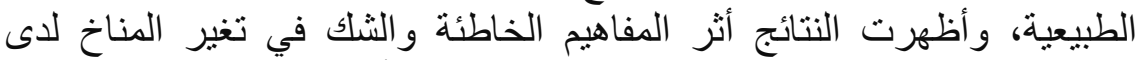
المعلمين على اتجاهاتهم نحو تعليم التغير المناخى، و أنه هناك نقص فئ في التدريب

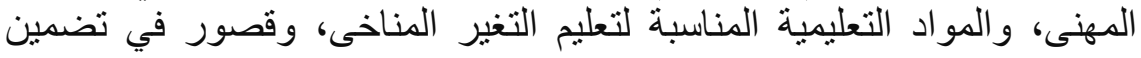
موضو عات تغير المناخ في المناهج الدراسية.

الإطار العام لمشكلة البحث: بالنظر إلى حالة التغير المناخى في مصر ، و الجهود المبذولة للتصدى إلهى اللى هذه

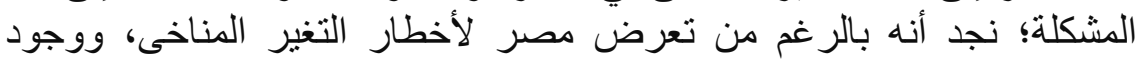

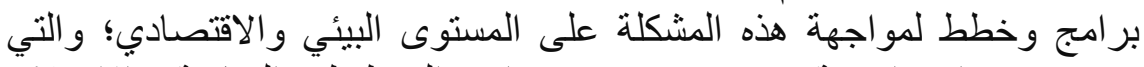
تتضح في استراتيجية مصر 2030 (وزارة التخطيط والمتابعة والإصدالاح

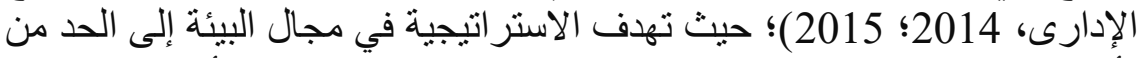

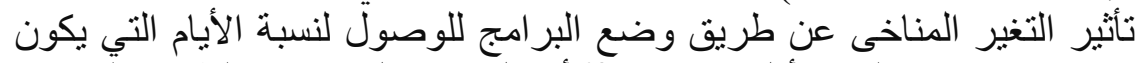
فيها مؤشر جودة الهو اء أقل من 100 1 أفضل من دول دول مشابهة الطبيعة المناخية، 
ومضاعفة معدل التحسن في فعالية استخدام الطاقة بحلول عام التور 2030 (رئاسة

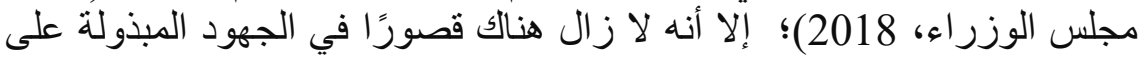

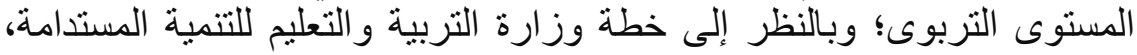

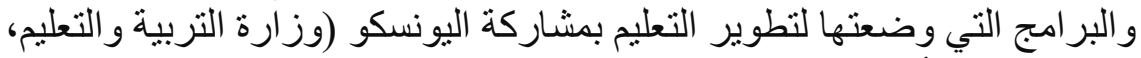
2018)؛ نجد أنها تضمنت إطارًا للعمل لتطوير التعليم في مرحلة التعليم قبل التبل

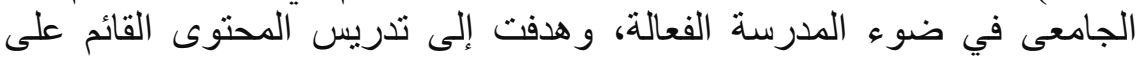

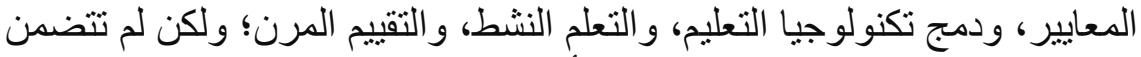

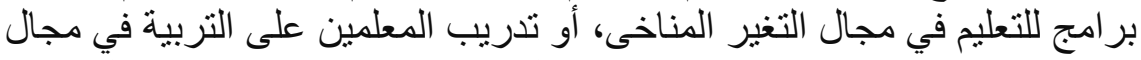

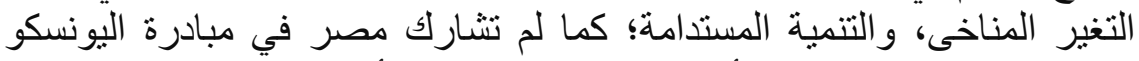

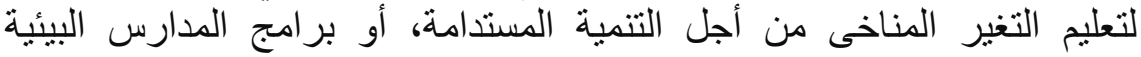

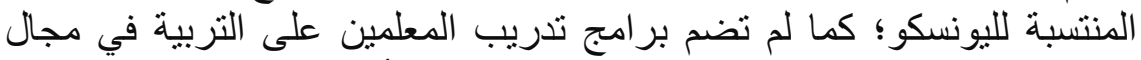

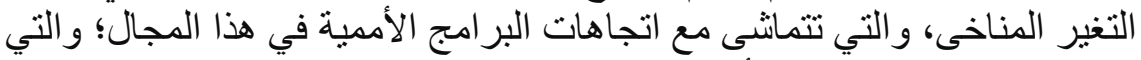

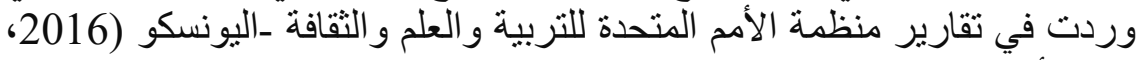

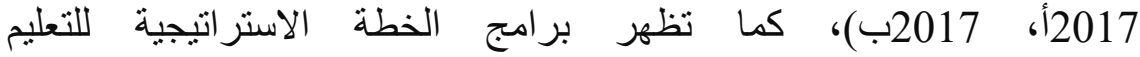

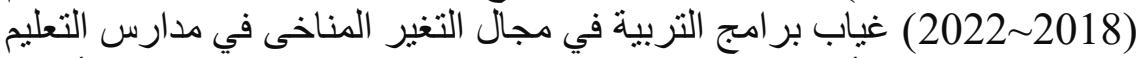

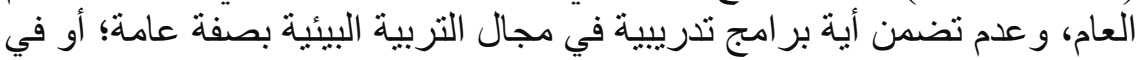

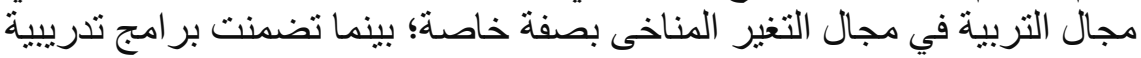

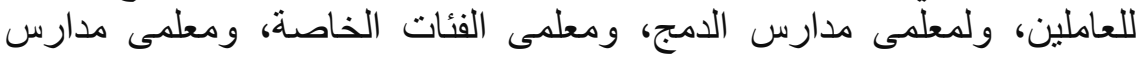

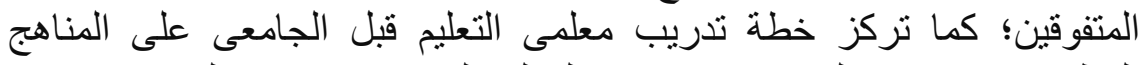

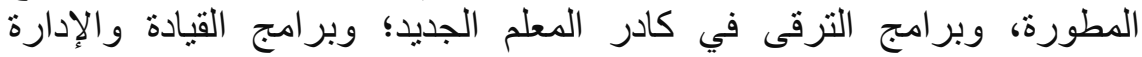

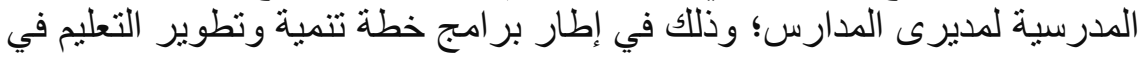

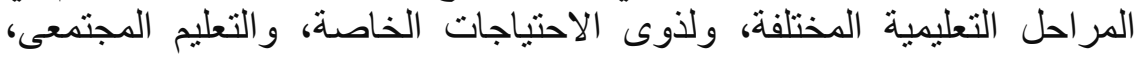

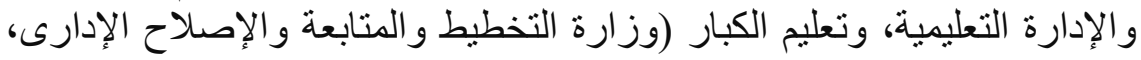

ومن هنا تتحدد مشكلة هذه الورقة البحثية في ضعف تركية أتركيز أهداف التعليم قبل

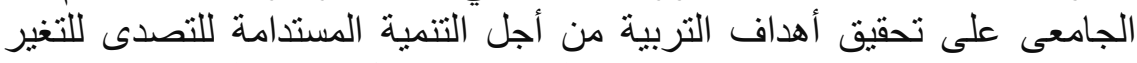

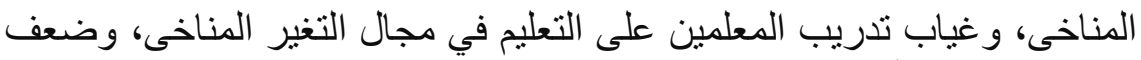
الاهتمام بتحقيق أهداف المدرسة الثاملة في الخطة الاستراتيجية لتطوير التعليم

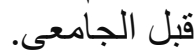

$$
\text { ويدعونا ذللك للإجابة عن السؤ الين التاليين: }
$$

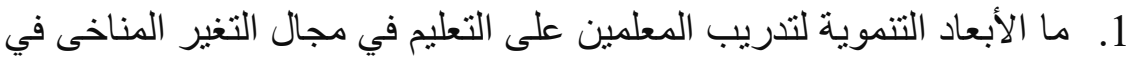

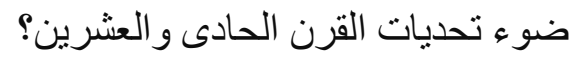
2. ما المبادئ التي يجب أن يقوم عليها تدريب معلمى التعليم قبل الجامعى على التى

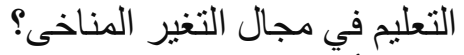

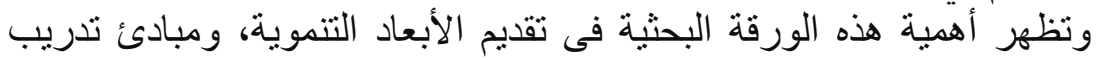

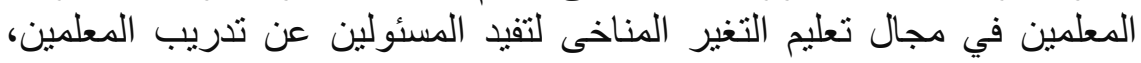
والخبراء المنوطين بإعداد برامج وخطط التدريب القومية في مجال التنمية 
المستدامة إلى العمل على خلفية تنموية ومبادئ واضحة لحفز تدريب المعلمين في

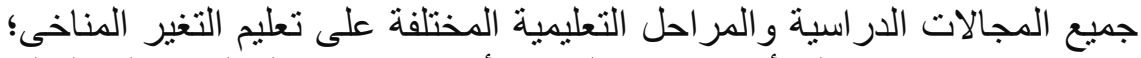
وبناء بر امج تدريبية على أسس تنموية لتحقيق أهداف تدريب المعلمين على التعليم

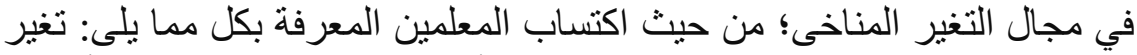
المناخ، ومرونة واستدامة و استقر ار المناخ، وأهداف التنمية المجتمعية، وأهداف

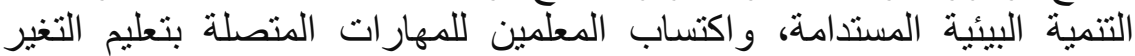
المناخى وهى كالتالى: التفكير النقدى، وتصور السيناريو هات المستقبلية، واتخاذ

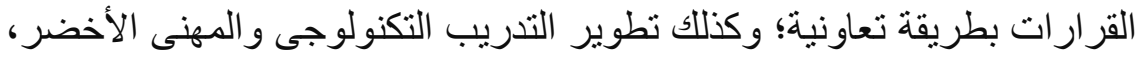

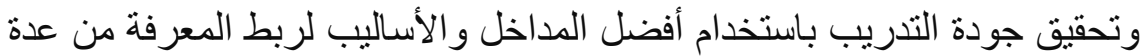

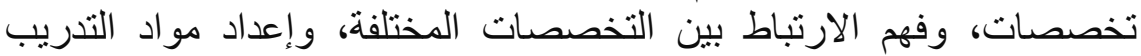
المتعلقة بالتغير المناخى من عدة نواحى علمية ونتاريخية وجغر افية وسياسية،

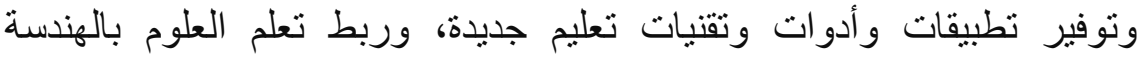

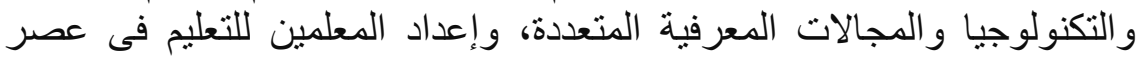
المعرفة.

ويتحدد الهدف من هذه الورقة البحثية إلى تحديد الأبعاد التتموية، والمبادئ

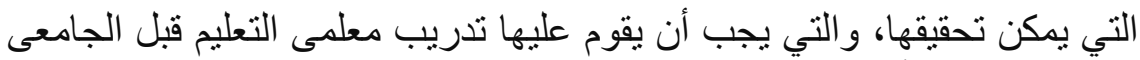
على التعليم من أجل التغير المناخى في إطار المدرسة الثـاملة لمواجهة تحديات القرن الحادى و العشرين.

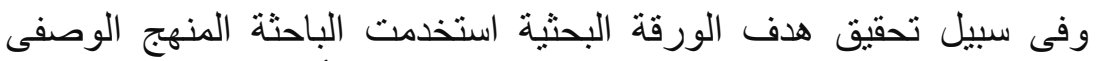
الاستقرائى لبحث إثكالية التغير المناخى، والتربية من أجل التنمية المستدامة؛ لتحديد الأبعاد التنموية، ومبادئ تدريب المعلمين على التعليم في مجال التغير

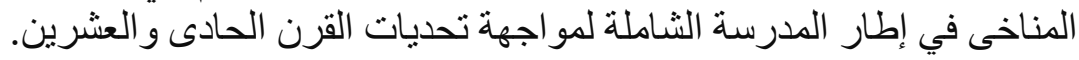

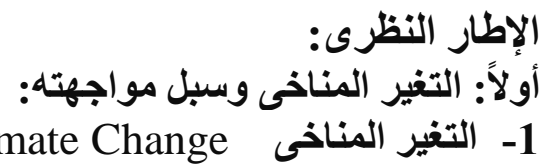
1- التغير المناخى

التغير المناخى هو اختلال يحدث في طبقات الغلاف الجوى مثل: درجة الحرارة وهطول الأمطار ومعدل الرياح، و غير ها من التغيرات التي فئي فئم قياسها

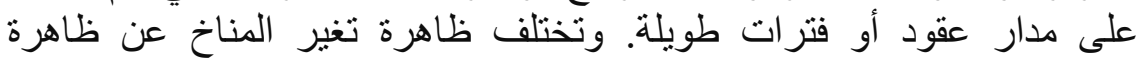

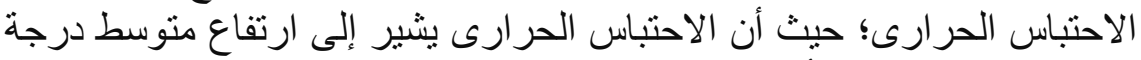

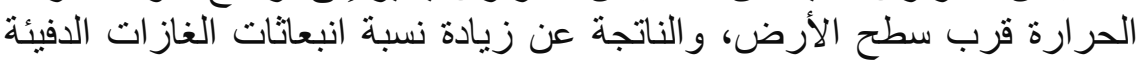

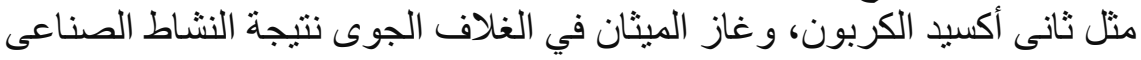
البشرى المتز ايد (Australian Academy of Science, 2015). حددت الأمم المتحدة الهدف الثالث عشر من أهداف التنمية المستدامة في

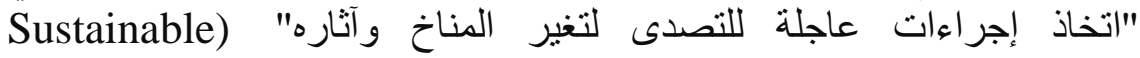
الجفانق)، وبرزت مشكلة التغير المناخى من خلال الحقائق التالية: 


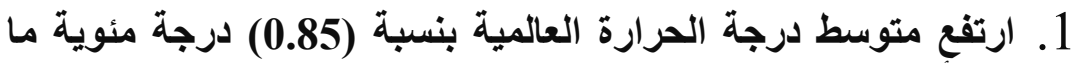

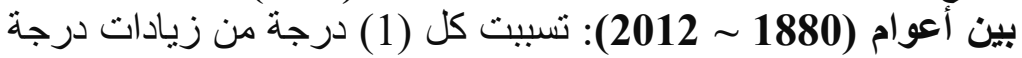

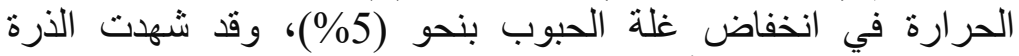

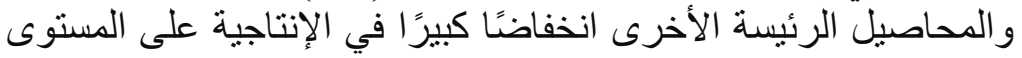

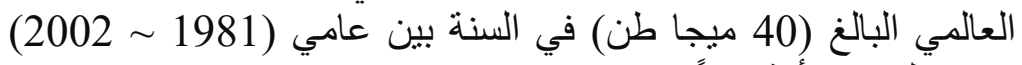
بسبب آلمناخ الأكثر دفئًا.

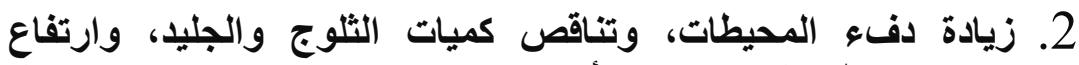

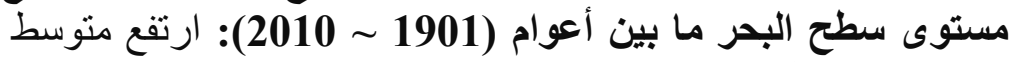

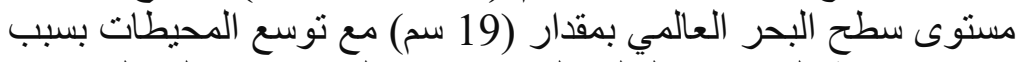

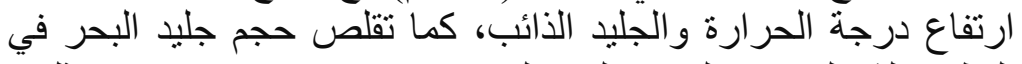

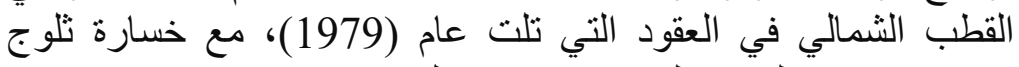

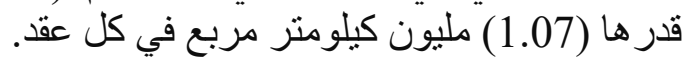

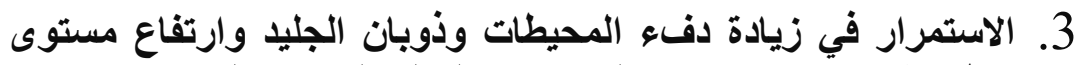

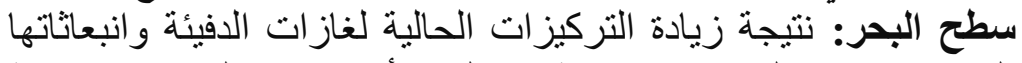

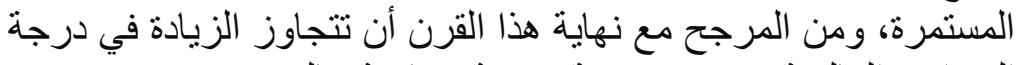

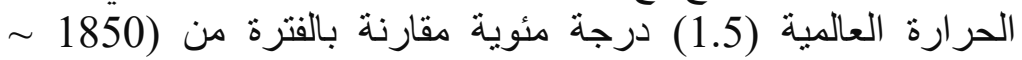

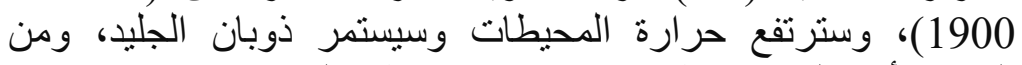

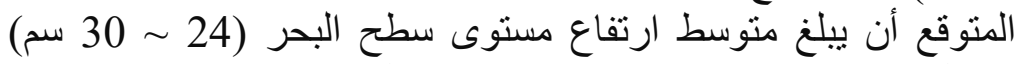

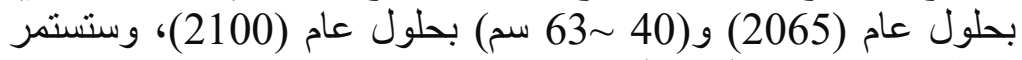

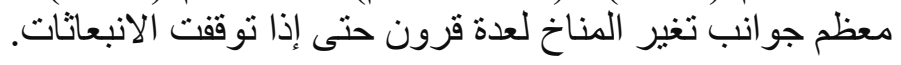

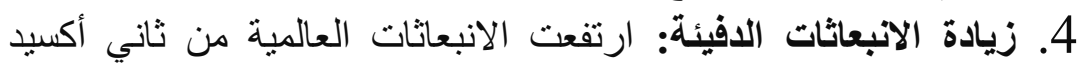

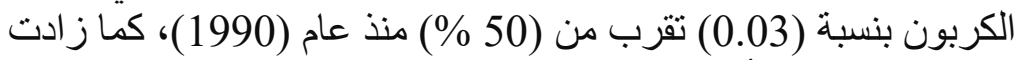

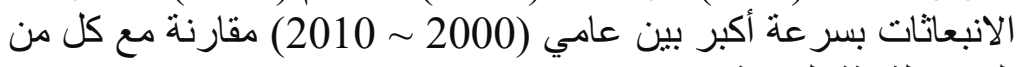

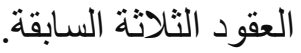

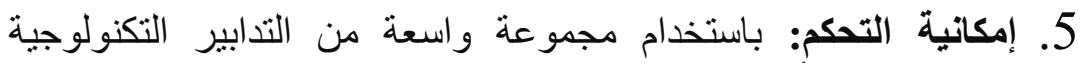

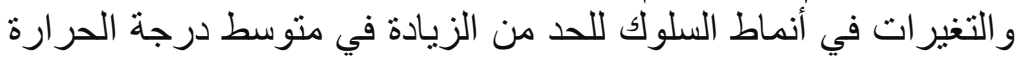

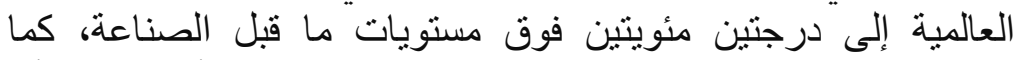

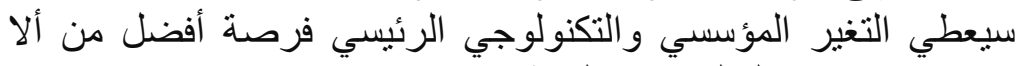
يتجاوز الاحتر ار العالمي هذه العتبة.

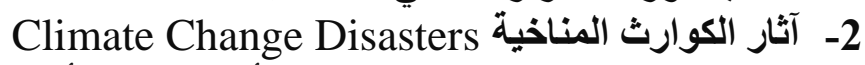
تعتبر المخاطر و الكوارث المناخية من أحد الفئات الأربعة التي تصنفها وحدة

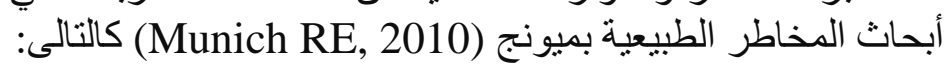

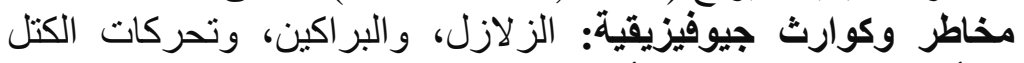

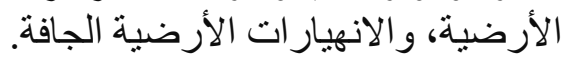

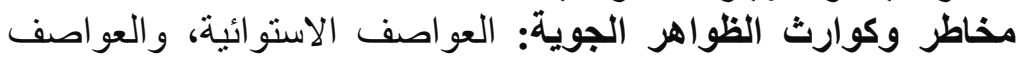
المدارية، و العو اصف المحلية. 
مخاطر وكوارث هيدرولوجية: فيضانات الأنهار، و السيول، والأمواج

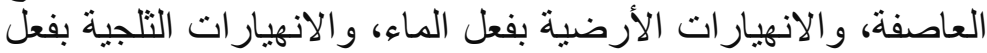

الماء، و السقوط الصخرى بفعل الإن الماء.

مخاطر وكوارث مناخية: الموجات الحراءية (الحارة و الباردة)، و الثتاء

$$
\text { القارص، و الجفاف، وحر ائق الغابات. }
$$

ونجد أن العناصر المؤثرة على نمو الانبعاثات الحراتية العاتية نرتبط بكل من:

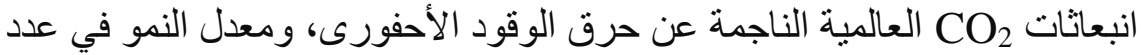
السكان، ومعدل النمو في الناتج المحلى الإجمالى GDP لكل فرد الأل

(RE, 2010)

ولذللك تأثيرات بيئية عديدة تتمثل في: ذوبان الجليد، وارتفاع مستويات المياه

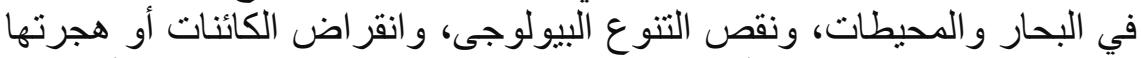

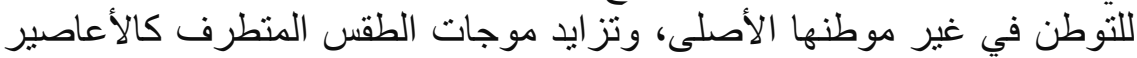
و العو اصف في والفيضانات.

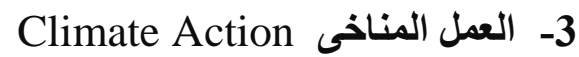

أفادت الهيئة الحكومية الدولية المعنية بتغير المناخ (IPCC) في تقييم جديد،

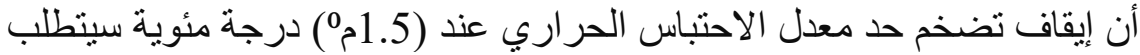

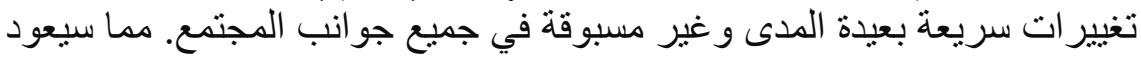

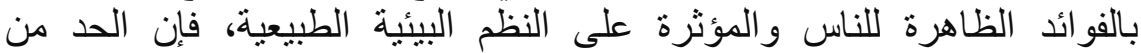

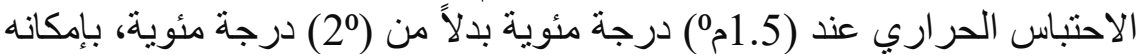

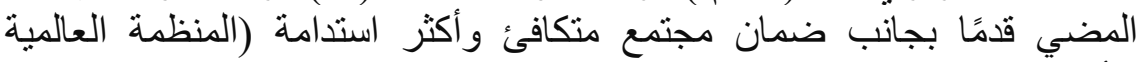
ل ل لأرصناد الجوية، 2019).

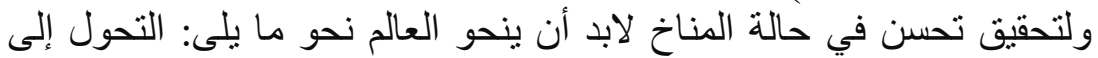

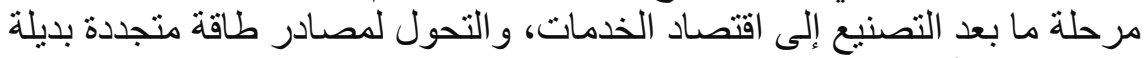

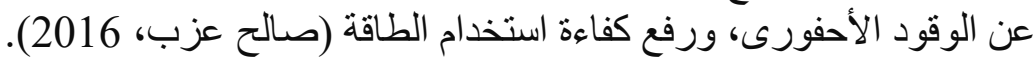

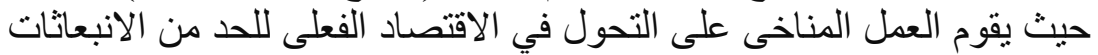

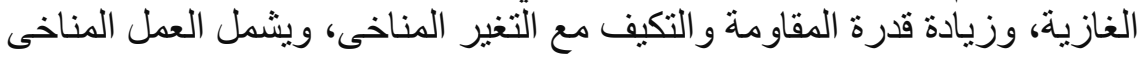

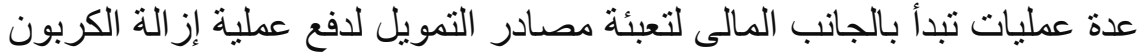

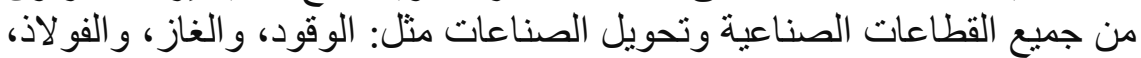

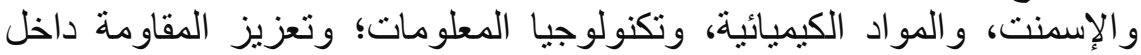

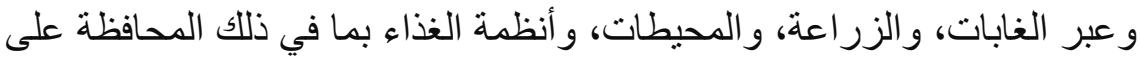

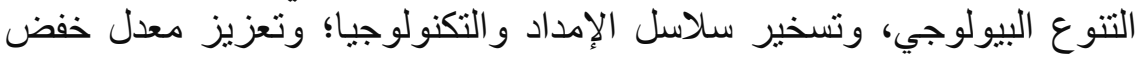

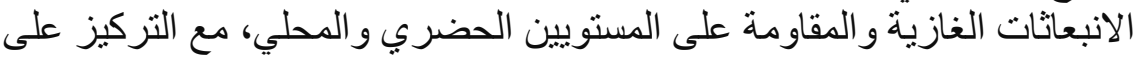

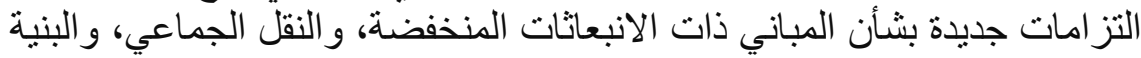

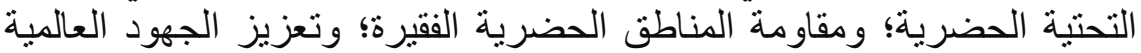

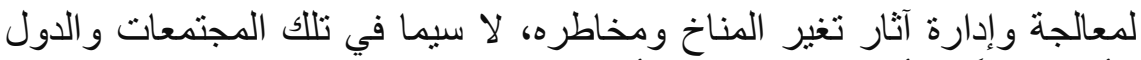
الأكثر ضعفًا (الأمم المتحدة، 2019 أنغير). 
ويتم العمل المناخى من خلال ثلاثة مجالات رئيسة هي: استراتيجية خفض في الاتئ

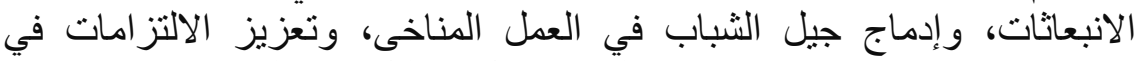

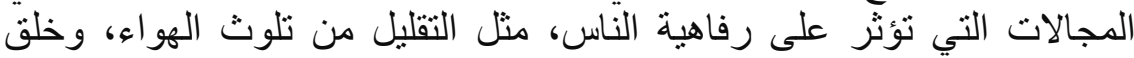
فرص عمل لائقة، وتقوية استر اتيجيات التكيف مع المناخ، وحماية العمال و الفئات

\section{4- طرق مواجهة التغيرات المناخية:}

يعد تغير المناخ من المخاطر الطبيعية التي ستؤدى إلى الفئل الفقر وإعاقة التنمية

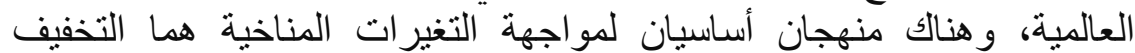

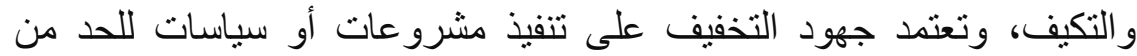

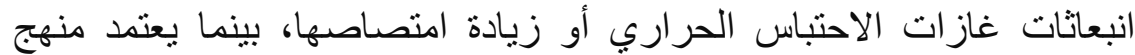

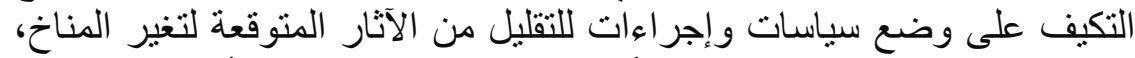

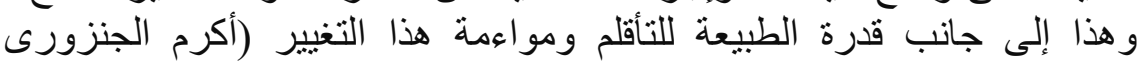

أ- تخفيف التغير المناخى Climate Change Mitigation:

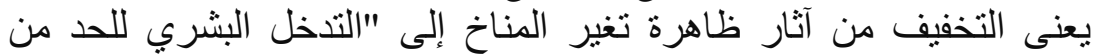

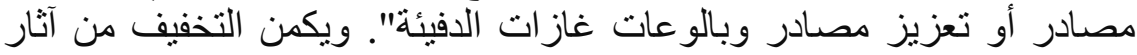

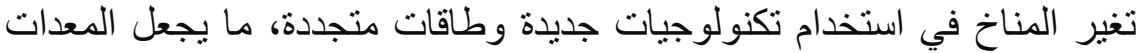

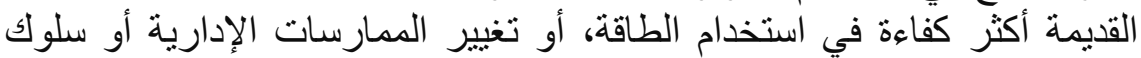
المستهرلك. ويتخذ برنامج الأمم المتحدة للبيئة نهجًا متعدد الأوجه من أجل التخفيف من فن التهاء

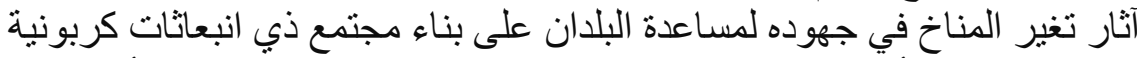
منخفضة ويمكن أن تكون هذه العملية معقدة مثل التخطيط لمدينة جديدة التهائ أو بسيطة

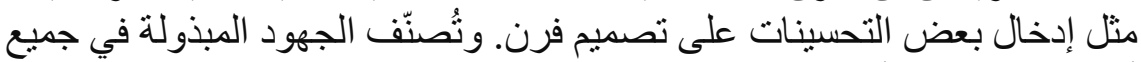

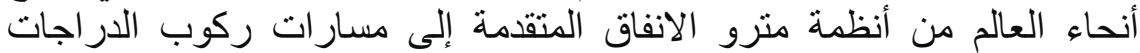

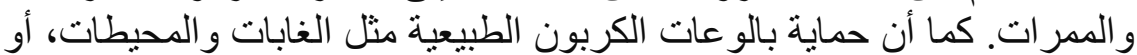

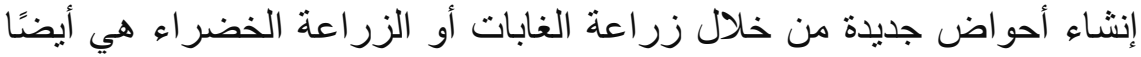

عناصر تخفيف لآثار تغير المناخ، (EU Science Hub, 2018).

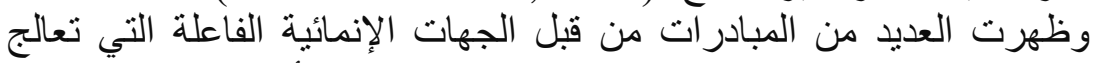

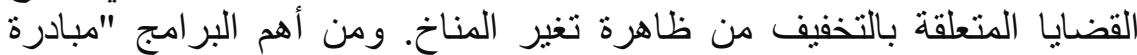

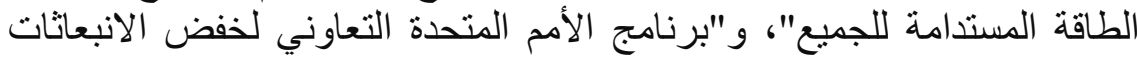

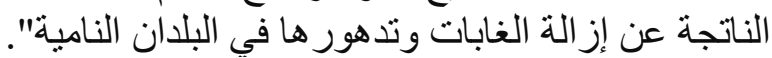

ب- التكيف مع التغير المناخى Climate Change Adaptation: التكيف مع التغير المناخى يمكن تعريفه على التهانه أنه الأفكار المرتبطة

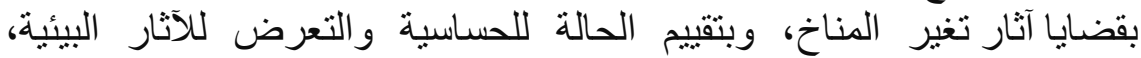

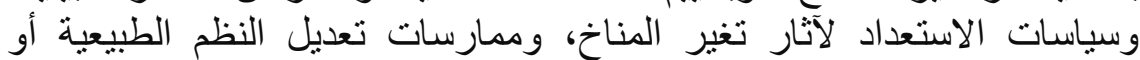

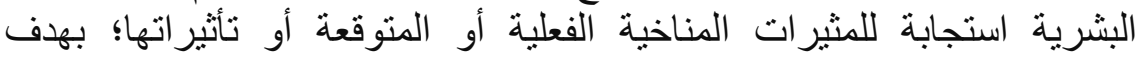




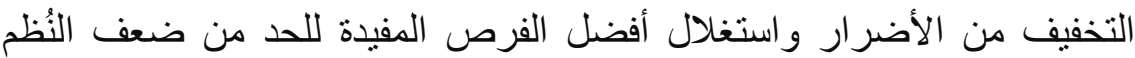

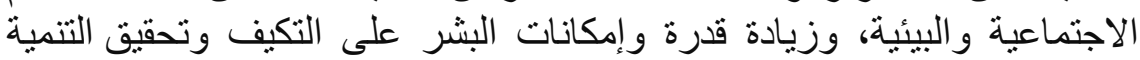

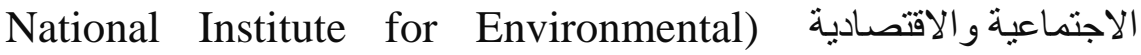
.(Studies, 2017

حيث أشنار سانتيجو (2001) إلى المفاهيم و القضايا وأساليب التقويم المتعلقة

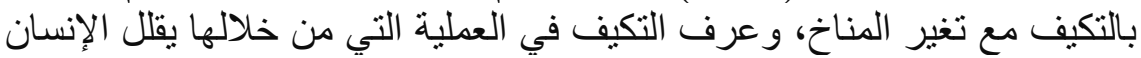

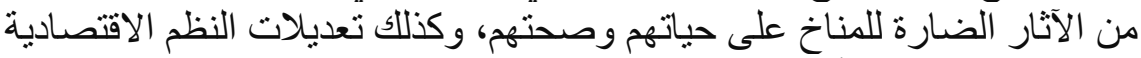
و الاجتماعية لتقليل الأخطار على المدى الطويل، وركز على بلى بيان محددات التئيف

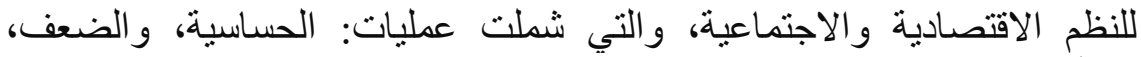
والتأثثر المحتمل، والمرونة والاستجابة، والنية، والسعة التكيفية، والقدرة على التكيف .(Santiago, 2001)

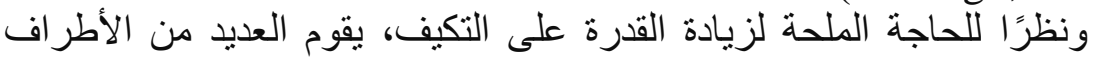

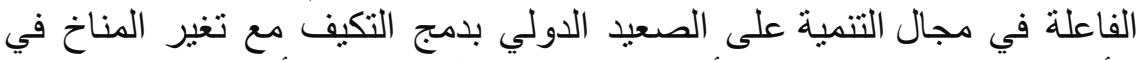

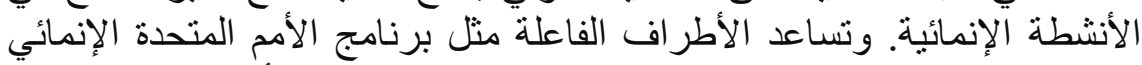

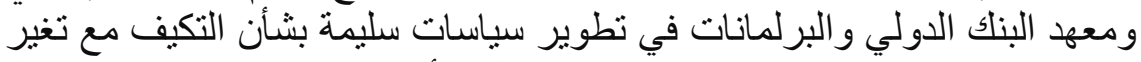

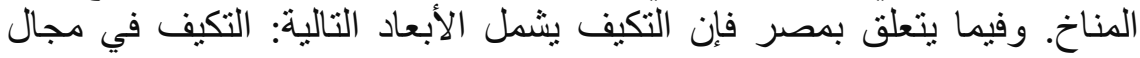

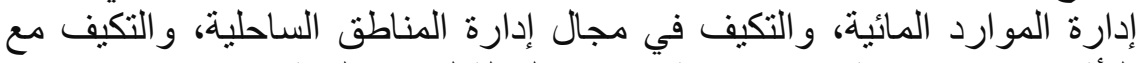
التأثثر ات الاجتماعية والاقتصادية (وزارة الدولة لثئون البيئة، 2016).

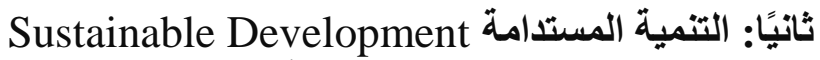

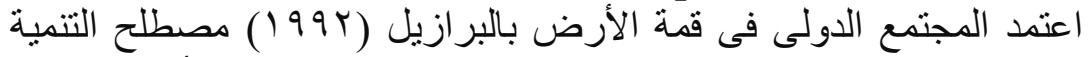

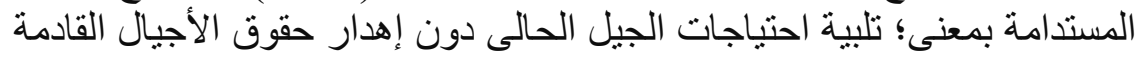

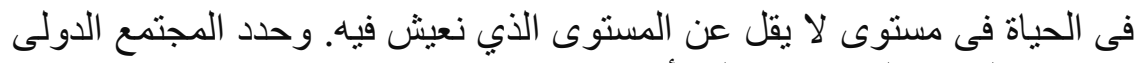

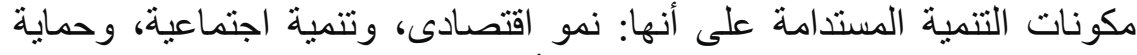

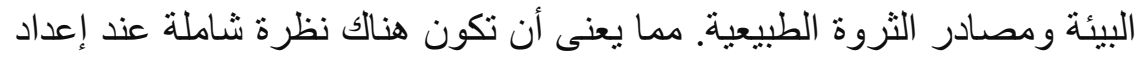

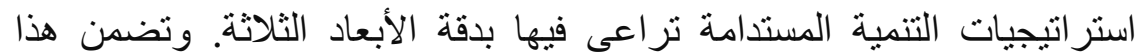
التعريف ثناثة أفكار رئيسة هي: التئئ

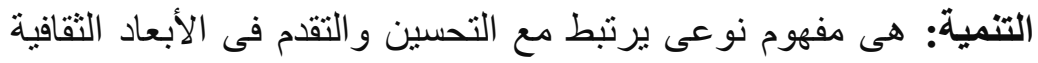
و الاجتماعية و الاقتصادية مفتوم نوعية

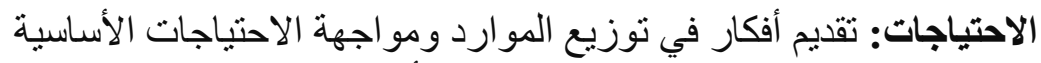

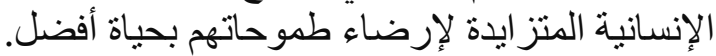

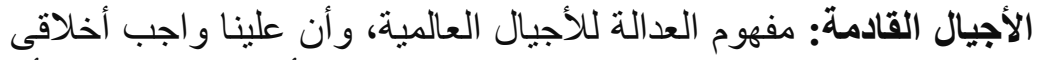

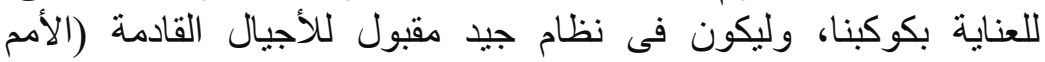

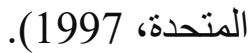
ويهدف البعد البيئى فى التنمية المستدامة إلى تحقيق العديد من الأهداف البيئية،

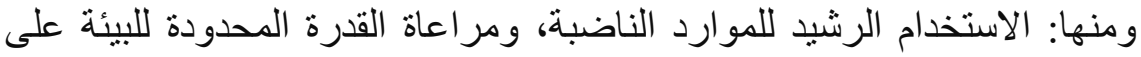
استيعاب النفايات، وضرورة التحديد الدقيق للكمية التى ينبغى استخدامها من كل 
مورد من الموارد الناضبة، و التوفيق بين التنمية الاقتصادية و المحافظة على البيئة

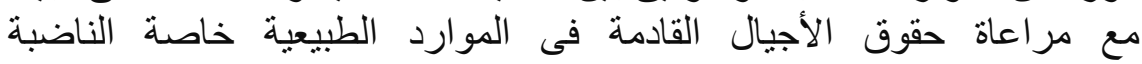

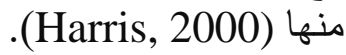

وفى هذا الصدد صدرت العديد من التقارير العالمية المنبيتة عن مؤتمر ات قمة التمة التئة الأرض وتغير المناخ تدعو إلى تحقيق استر اتيجيات مستقبلية لتحقيق التنمية البيئية التئية

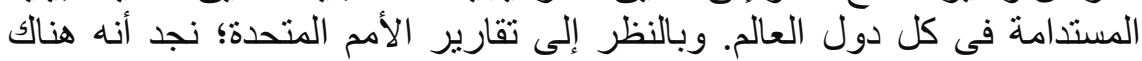

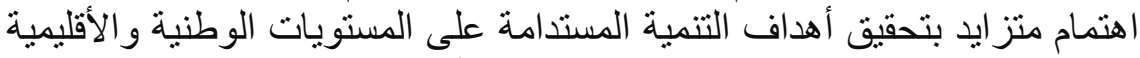

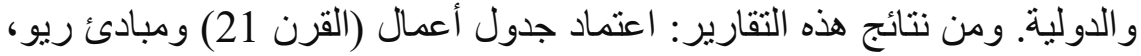

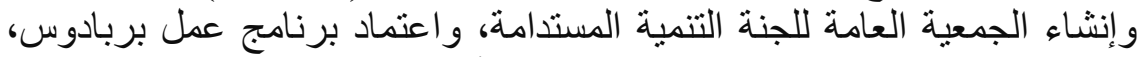

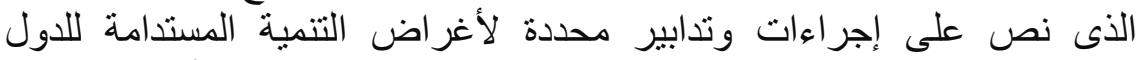

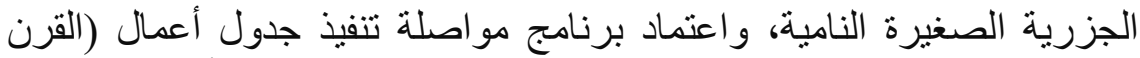

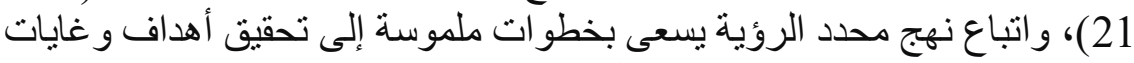

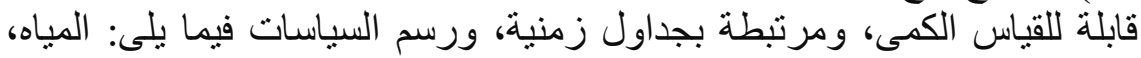

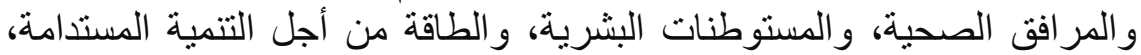

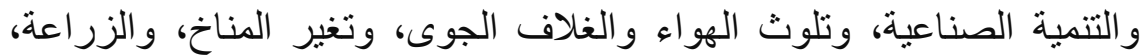

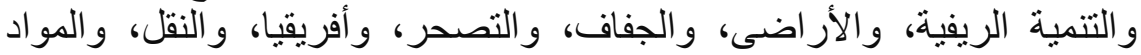

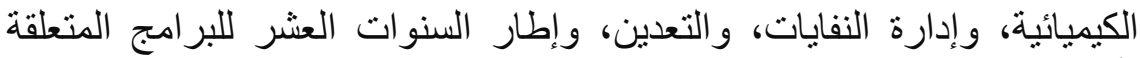

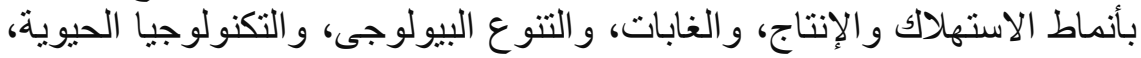

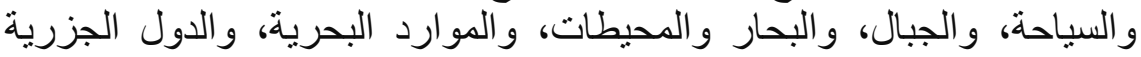

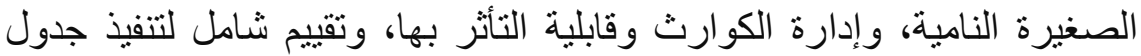

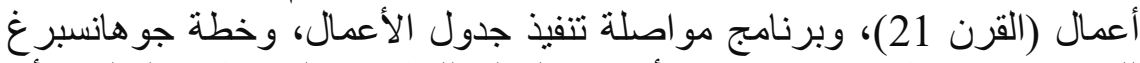

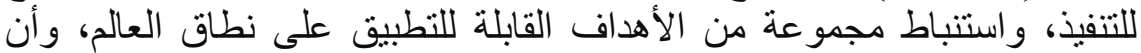
يو ازن بين الأبعاد الثلاثة للتنمية المستدامة: البيئية، والاجتماعية، ولافية والاقتصادية.

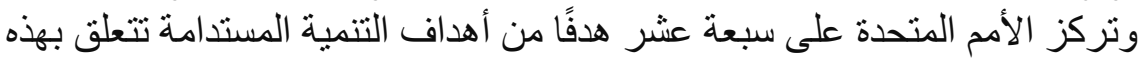

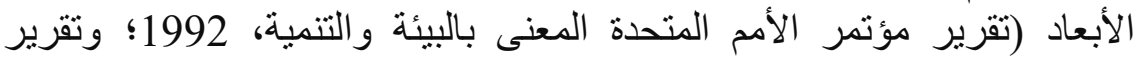

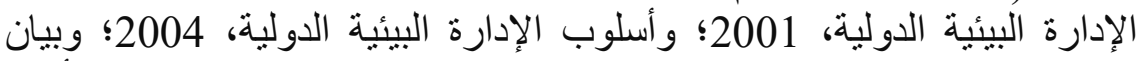

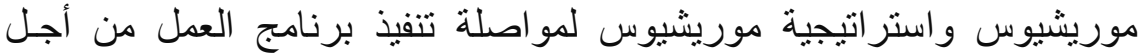

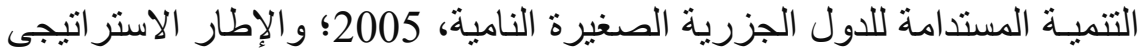

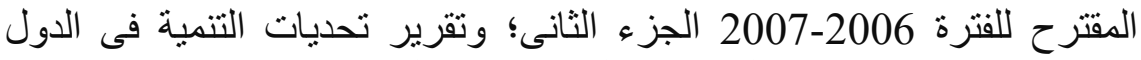
العربية، 2012؛ وقضايا السياسات العامة: حالة البيئة: البيئة والتنمية، 2013 2013؛

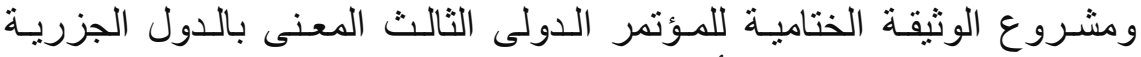

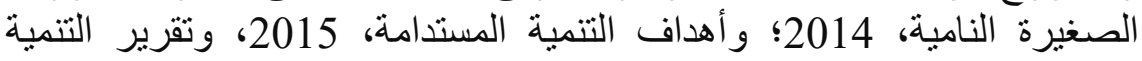

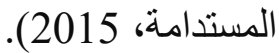
أوضحت مقاصد و غايات أهداف التتمية المستدامة (2015) في مجال التغير

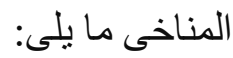


1. تعزيز المرونة والقدرة على الصمود في مواجهة الأخطار المرتبطة بالمناخ

و الكوارث الطبيعية في جميع البلدان، وتعزيز القدرة على التكيف مع تلكي

الأخطار.

2. إدماج التدابير المتعلقة بتغير المناخ في السياسات و الاستر اتيجيات والتخطيط على الصعيد الوطني.

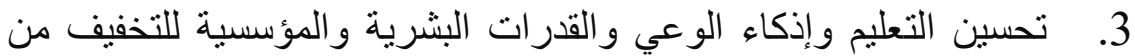

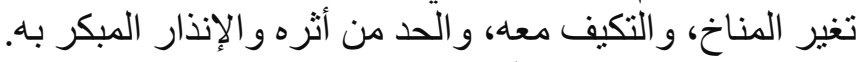

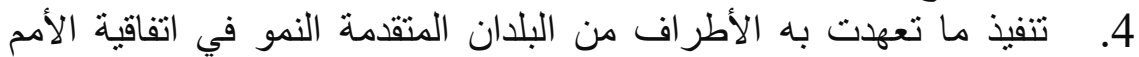

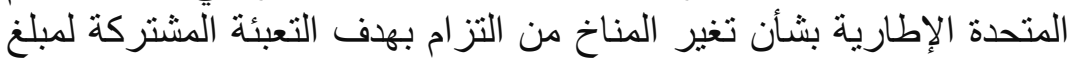

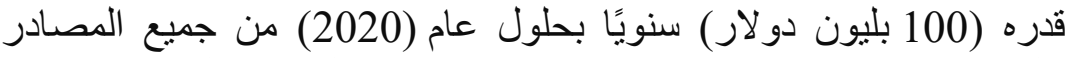
لتلبية احتياجات البلدان النامية، في سياق إجراء لاءت التيات التخفيف المجدية وشفافية

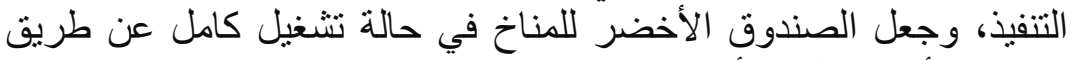
تزويده بر أس المال في أقرب وقت الأ مدكن. 5. تعزيز آليات تحسين مستوى قدرات التخطيط والإدارة الفعالين المتعلقين

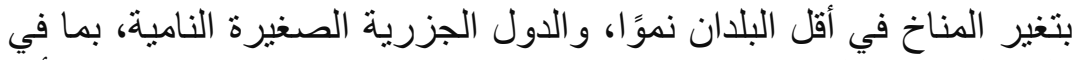

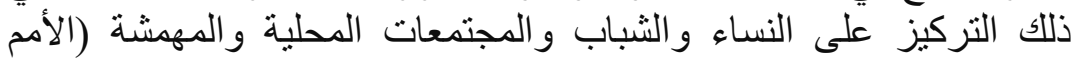

بالرجوع إلى تقارير حالة البيئة فى مصر (2018)؛ نجد أن مصر تواجه

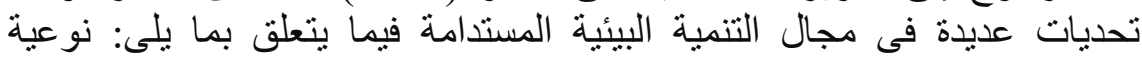

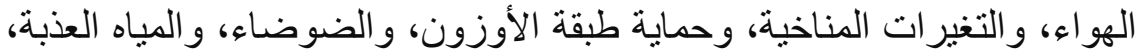

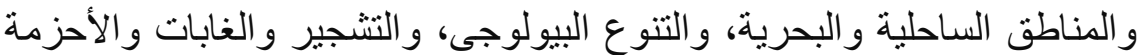

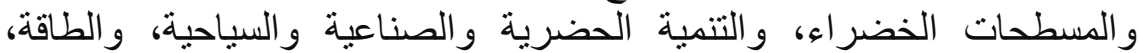

وحماية وتحسين البيئة الصناعية، و المخلفات الصلبة، و المو اد و النفايات الخطرة.

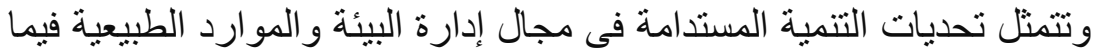
يلى: عدم إدراج الاعتبارات البيئية بثكل فعال فى السياسات القطاعية، وتركيز

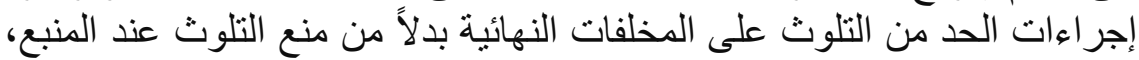
و النمو السكانى المطرد، و القصور فى توفير نظام متكامل لإدارة المخلفات خاصة

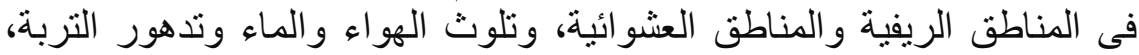
و المعالجة غير الكاملة لمباه الصرف الصحى و الصناعى، ومحدودية استخدام مياه

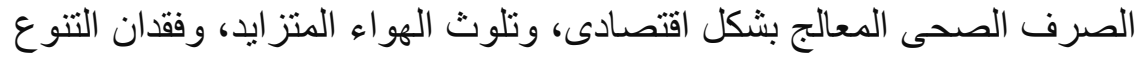

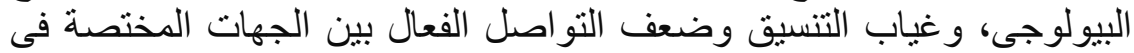

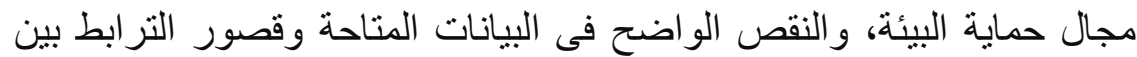
مراكز المعلومات البيئية، وقلة الاعتمادات المخصصة للمشرو المات فات المتعلقة

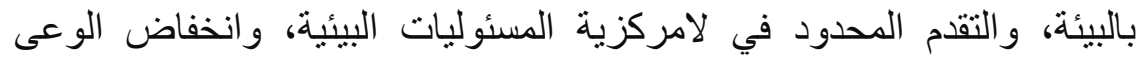
البيئى، وسوء الممارسات التى تؤثر سلبًا على كفاءة نظم الإدارة البيئية المتكاملة،

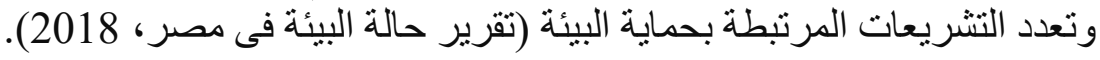


وحددت اللجنة الوطنية للتنمية المستدامة أهداف التنمية البيئية المستدامة فى المئي

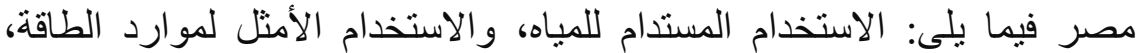

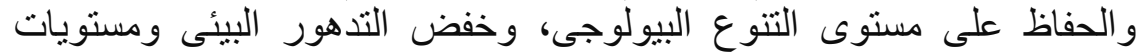

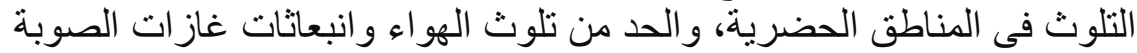

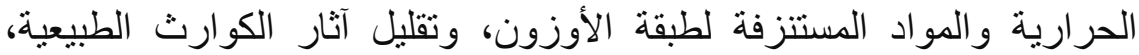

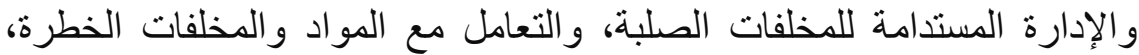
وزيادة الموارد والاستخدام الرشيد للمصادر الثروة المئدة الطبيعية (اللجنة الوطنية ل للتنمية المستدامة، 2008).

كما تسعى استر اتيجية التنمية المستدامة (مصر 2030) فى مصر إلى تحقيق

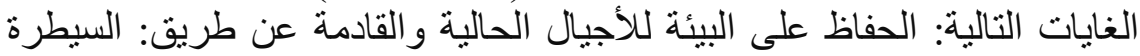

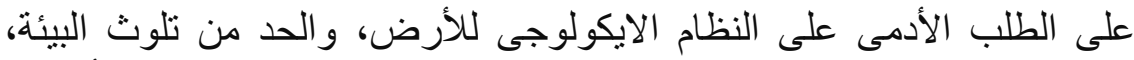
وحماية المحميات الطبيعية بما لا يتعارض الإكولمع النمو الاقتصادى. وتتمثل أهدافها

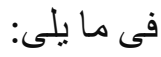

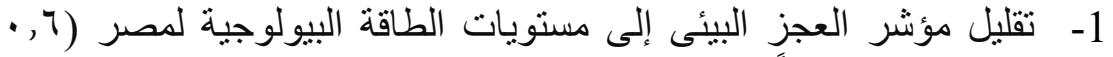

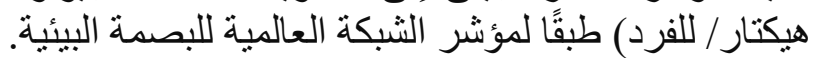

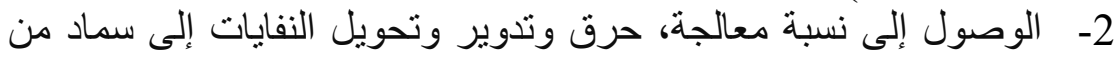

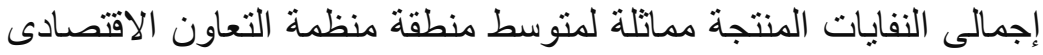

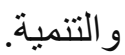

3- ت تقليل كثافة نوليد النفايات البلدية بالكيلوجر ام للفرد إلى مستوى منطقة

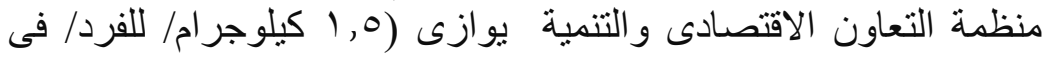
اليوم). 4- الوصول لمعدل معالجة مياه الصرف الصحى بساوى الأفضل فى المنطقة

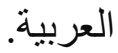

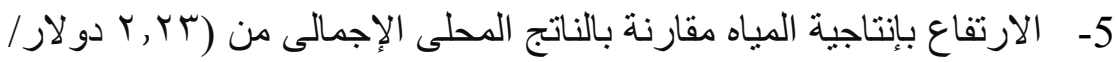

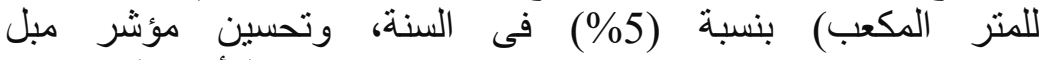

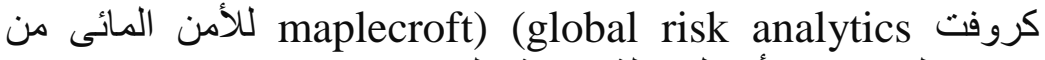

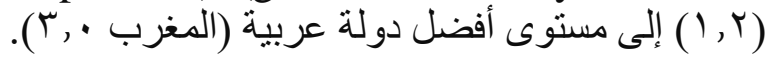

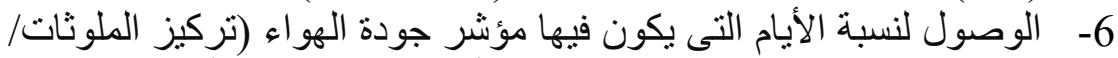

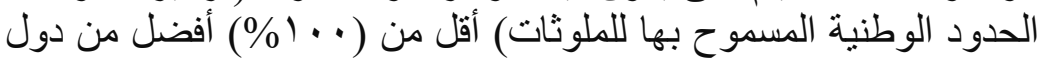
مشابهة فى الطبيعة المناخية.

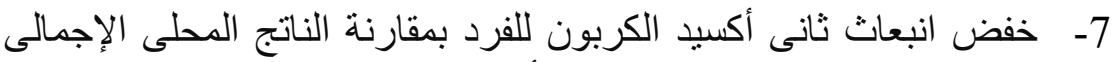

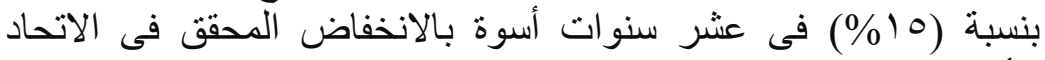
الأوروبى.

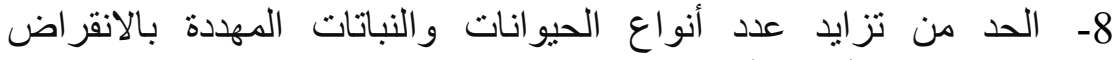

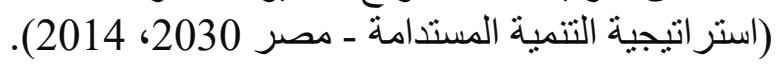

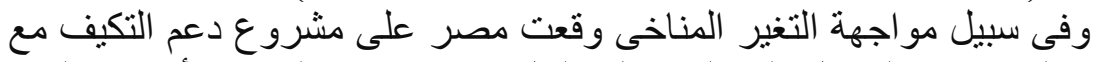

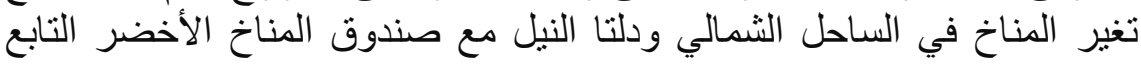


لبرنامج الأمم المتحدة الإنمائى، ويهدف المشروع إلى الحد من الفيضانات

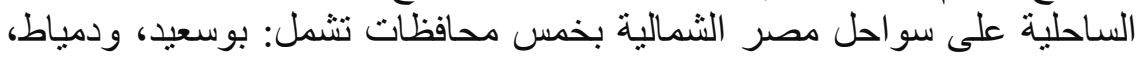

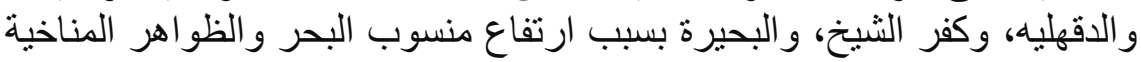

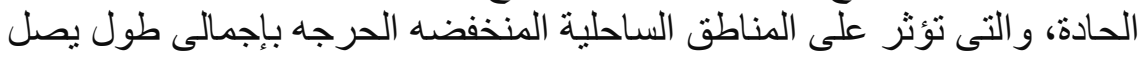

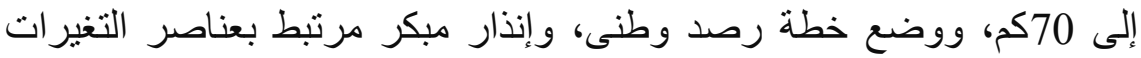
المناخية وارتفاع منسوب البحر ـ (وزارة الموارد المائية والرى، ولن، 2018)

Comprehensive School ثالثًا: المدرسة الشاملة يقصد بالمدرسة الثاملة المؤسسة التعليمية التي تقوم على مبادئ مستدامة في

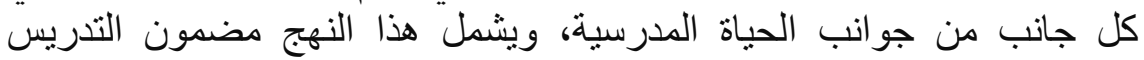

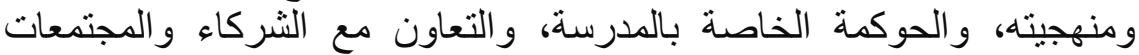

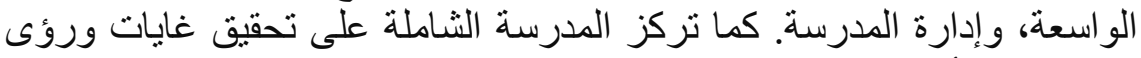

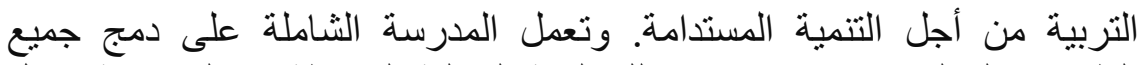

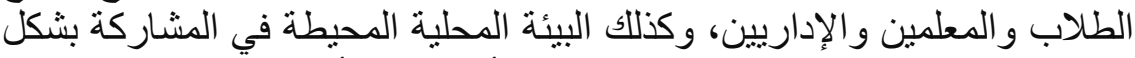

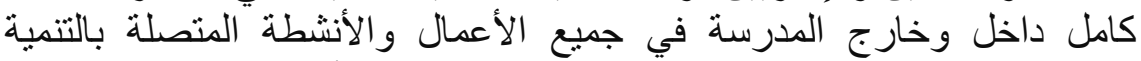

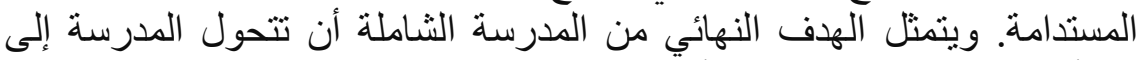

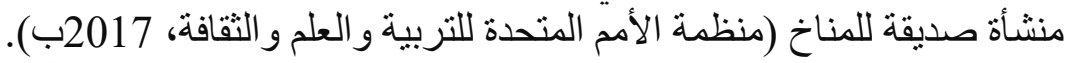

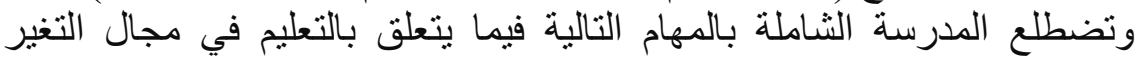

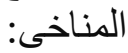
1- تشكيل فريق عمل معنى بالمناخ عبر المدرسة يتولى إعداد وتتفيذ ومر اجعة خطط المدرسة. 2- إجر اء تقييم للالتزامات و الأنشطة التي تقوم بها المدرسة بشأن التصدي

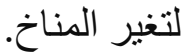

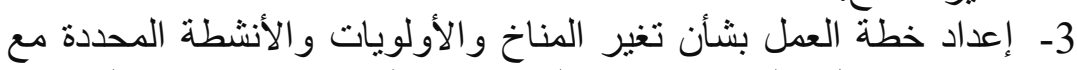

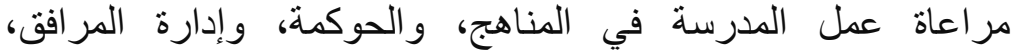

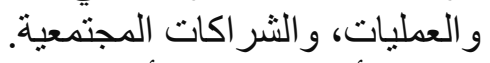

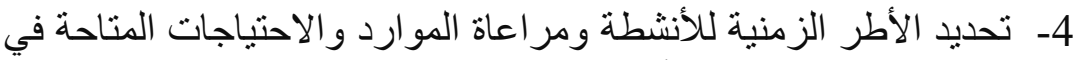

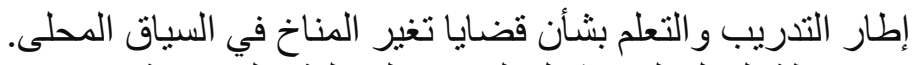

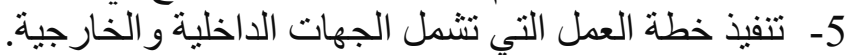

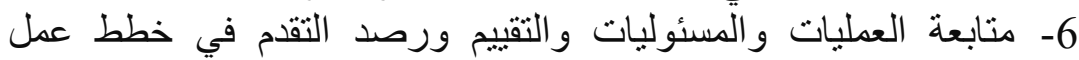
المدرسة.

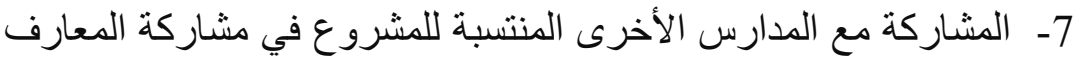

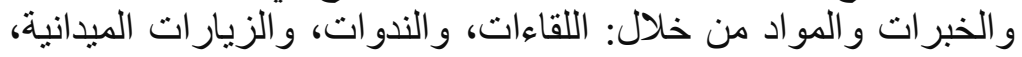

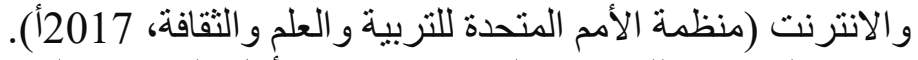

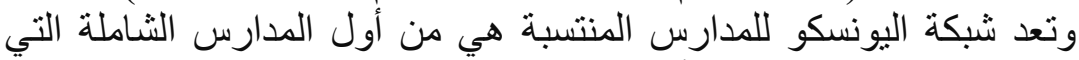

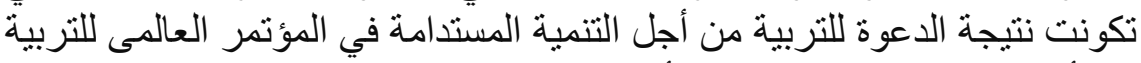
من أجل التنمية المستدامة الذى أقيم فى إيثى ناجويا باليابان (2014). و إعداد التئ 
برنامج العمل العالمى بشأن التعليم من أجل التنمية المستدامة، وتناول البرنامج

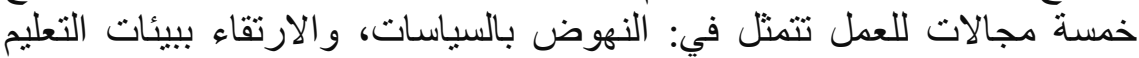

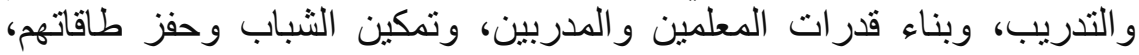

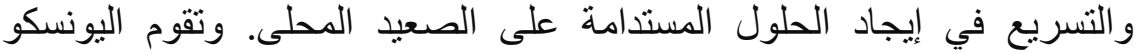
بتنسيق التنفيذ الثامل لبرنامج العمل العالمى المدعوم من حكومة اليابان (منظمة الفئ الأمم المتحدة للتربية والعلم والثقافة، 2014).

رابعًا: الجهود الأممية في مجال تدريب المعلمين على التكيف مع التغير

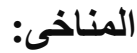
1 - تدريب المعلمين على التكيف مع تغير المناخ:

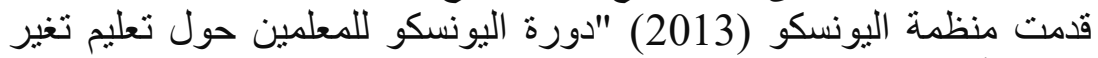

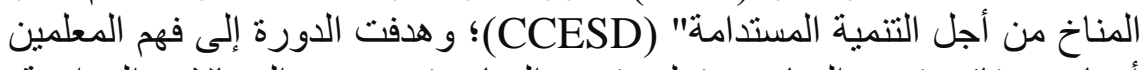

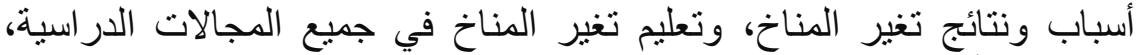

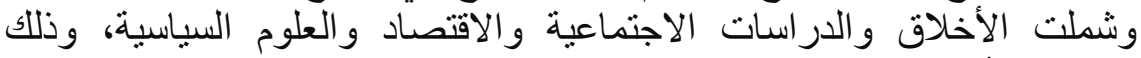

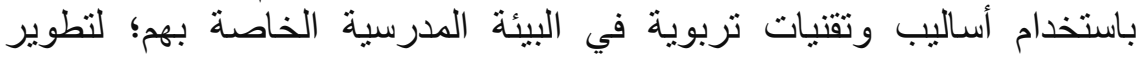

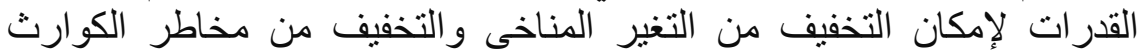

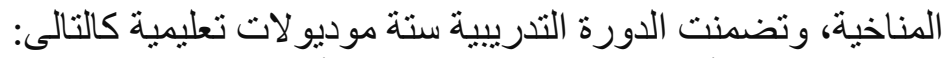

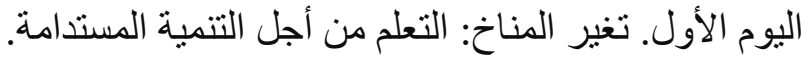

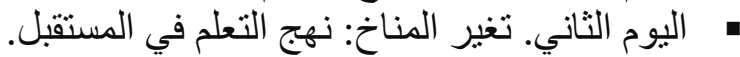

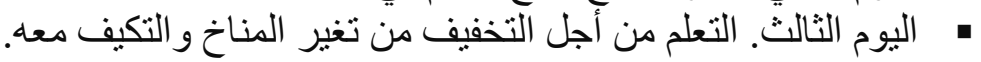
اليوم الرابع. تعلم تغير المناخ: تركيز محلي.

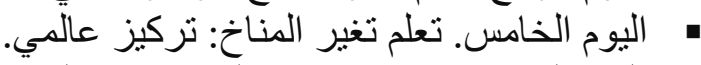

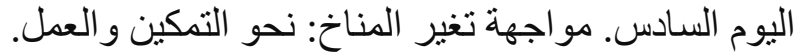

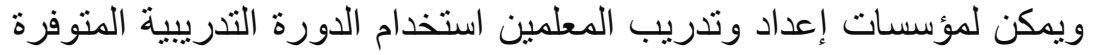

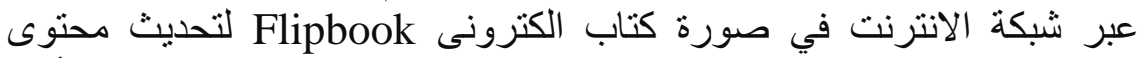

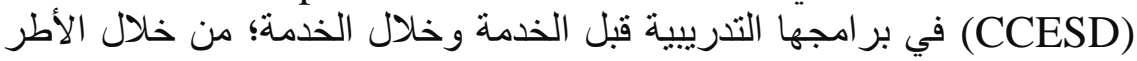

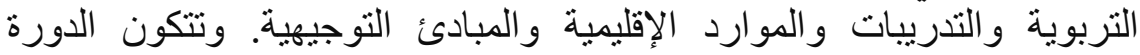

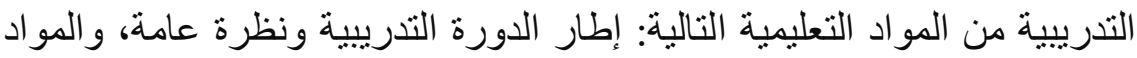
التعليمية لحقيبة تدريب المعلمين، وحزم الموارد الإقليمية، النية، ومواد الفصل الفية اليومية للمعلمين (UNESCO, 2013). 2- تدريب المدارس المنتسبة لليونسكو على التكيف مع تغير المناخ:

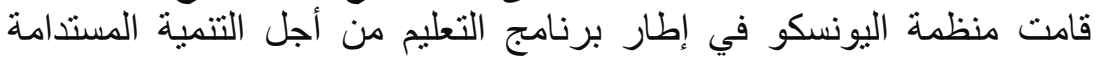

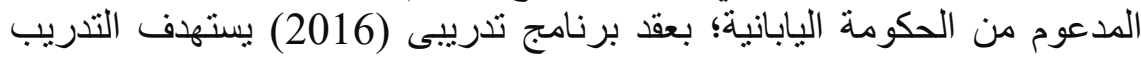

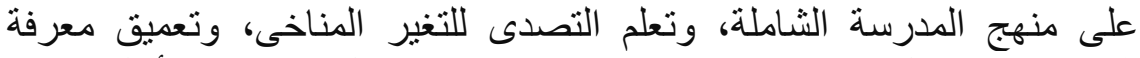

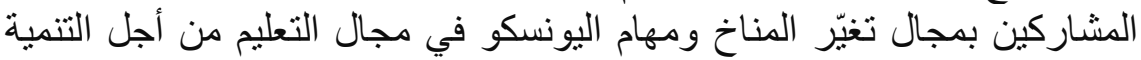

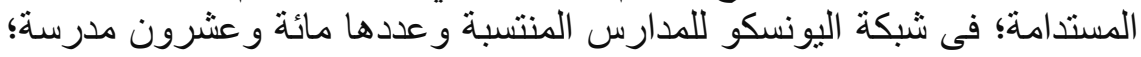
بمشاركة عدد من الدول الأعضاء منها: لبنان، وسلطنة عمان، و السنغال، ونامبيبا، ونياء 
وأندونسيا، وغير ها؛ وتضمنت الدورة التدريبية التي استمرت ثناثة أيام الدحاور

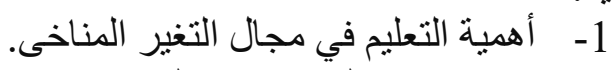

2- تعزيز قدرة المشاركين على رصد وتنسيق التغير المناخى على المستوى 3- تحديد الأطر اف المعنية الرئيسة داخل وخار ج المدرسة وطرق إدماجهم. 4- - رسم معالم التنمية المستدامة. 5- دور المدرسة وواجبها نحو التصدي للتغير التئنير المناخى. 6- ت تعزيز التعليم للتصدى للتغير المناخى.

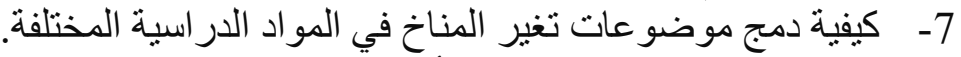

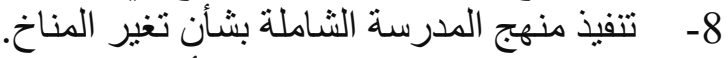
9- تدريب المعلمين في المدارس الأخرى.

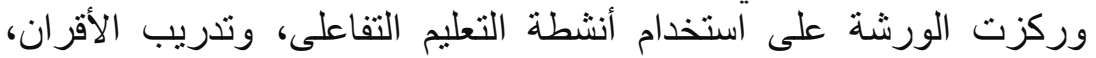

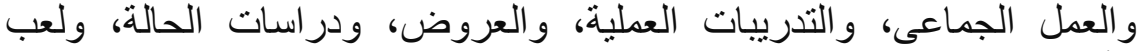

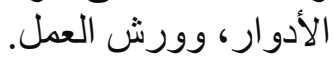

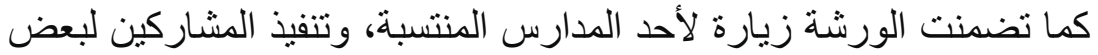

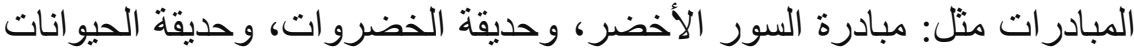

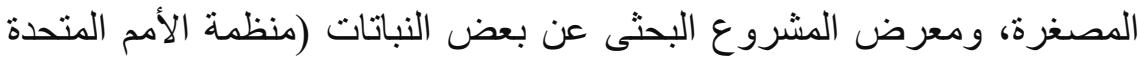
للتربية و العلم و الثقافة، 2016).

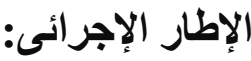

1- الأبعاد التنموية للتدريب على التعليم في مجال التغير المناخى:

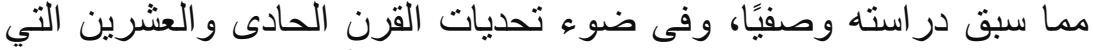

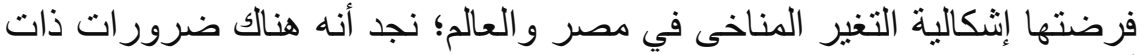

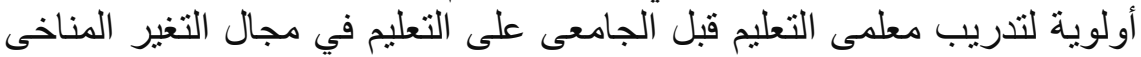
على أسس تنموية لتحقيق غايات التربية والتتمية، وتتمثل في الأبعاد التنموية التية التئية

\section{Environmental 1-1 التعليم من أجل التنمية البيئية المستدامة: 1-1}

:Sustainable Development ونظرًا إلى أن التربية تضطلع بعبء كبير في إعداد الأفراد القادرين على فئى

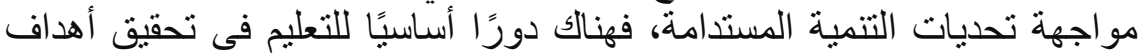

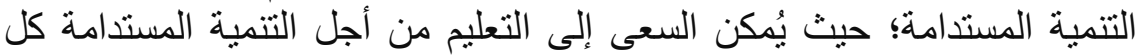

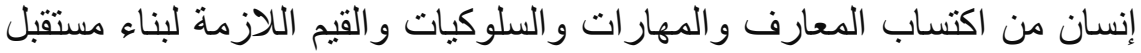

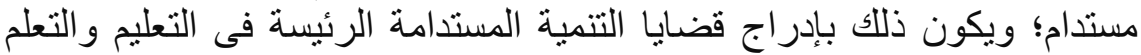

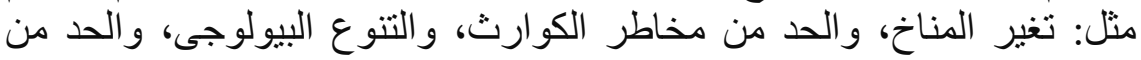


الفقر والاستهلاك المستدام؛ وتدريب المعلمين على تعليم مبادئ وأهداف التنمية

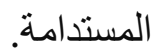

ويتطلب ذللك مناهج تشاركية خاصة بالتعليم والتعلم تحفز المتعلمين على تغيير سلوكهم وتمكنه من اتخاذ الإجراءات اللازمة لتحقيق التنمية المستدامة. كما كالفيا

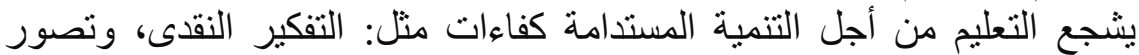

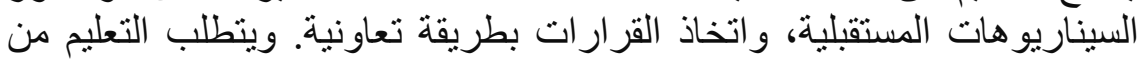

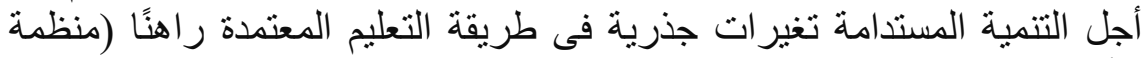
الأمم المتحدة للتربية و العلم و الثقافة، 2012). كما أقر إعلان إيشى - ناجويا (2014) قدرة التعليم من أجل التنمية المستدامة

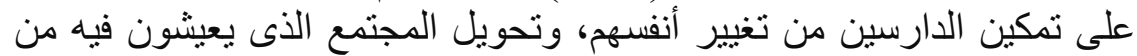

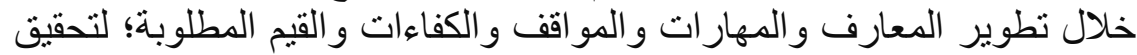

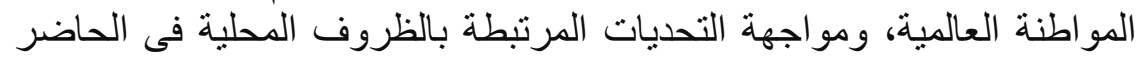

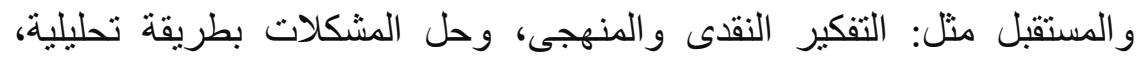

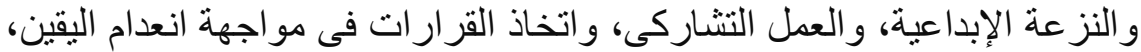

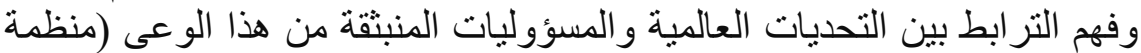
الأمم المتحدة للتربية و العلم و الثقافة، 2014).

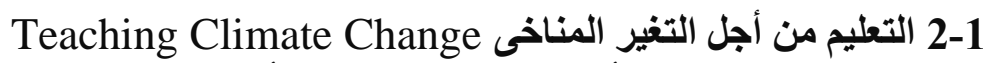
يظهر إطار شراكة الأمم المتحدة التعليم من أجل التغير المناخى (2013)

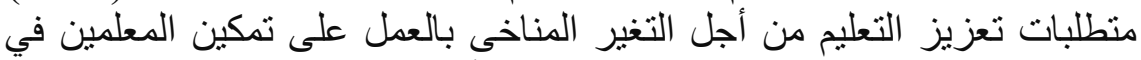

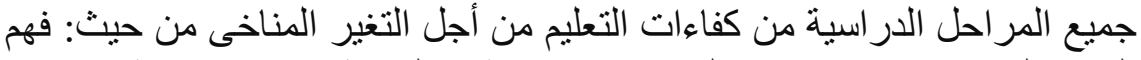

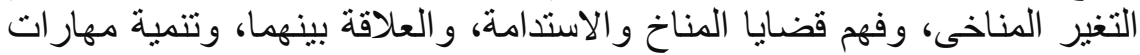

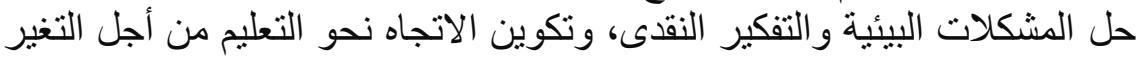

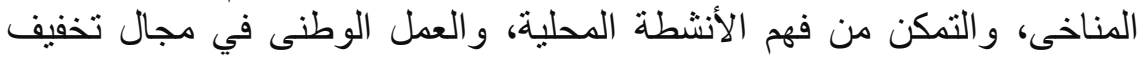

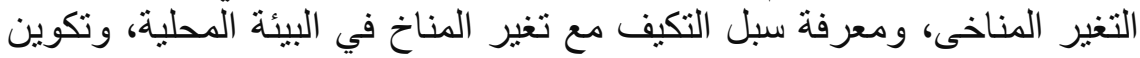
United Nation Institute for Training and الوعى البيئي والقيم البيمي البيئية

.Research, 2013

وفى هذا المجال أظهر اندرسون Anderson (2012) أهمية أن يكون التعليم

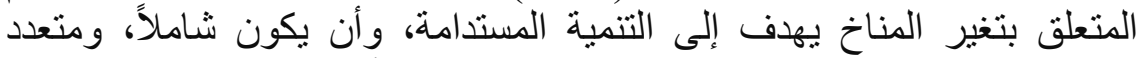
التخصصات، وهناك مكونين رئيسيين للتربية من أجل التغير التير المناخى هما:

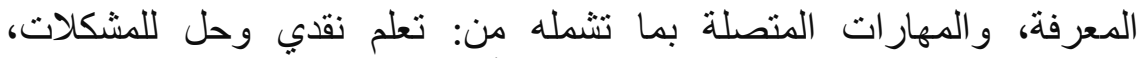

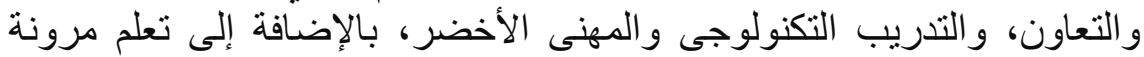
واستدامة واستقرار المناخ (Anderson, 2012).

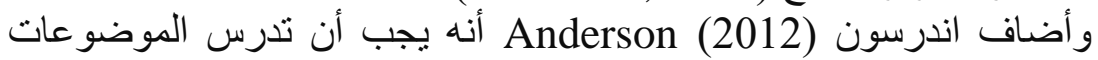

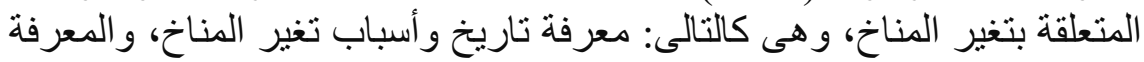

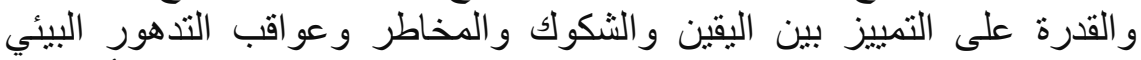
و الكوارث وتغير المناخ، ومعرفة ممارسات التخفيف و التكيف التي يمكن أن تسهر التين 
في بناء المرونة والاستدامة؛ وفهم المصالح المختلفة التي تشكل الاستجابات

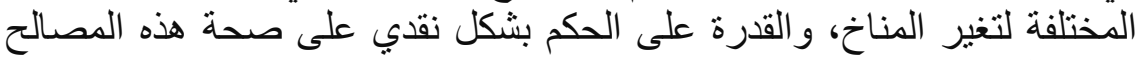
فيما يتعلق بالصالح العام (Anderson, 2012).

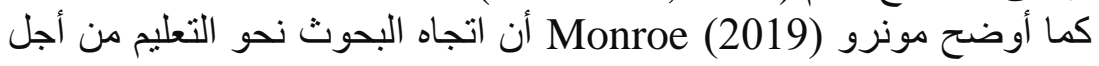

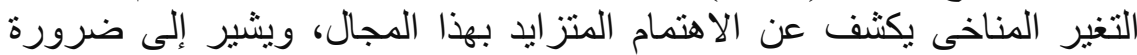

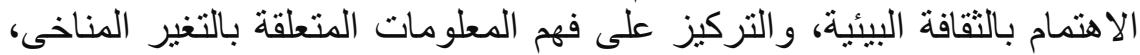

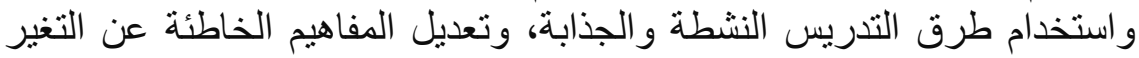
المناخى، وتتفيذ المشاريع المدرسية والمجتمعية (Monroe, 2019).

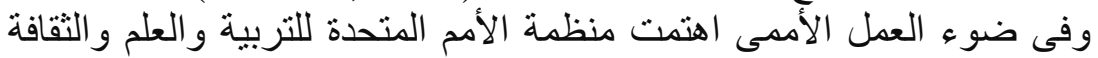

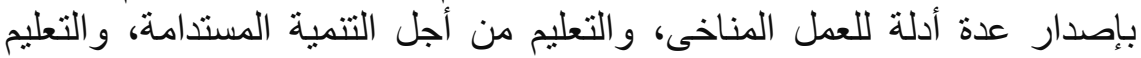

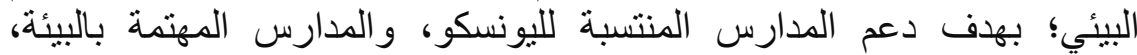

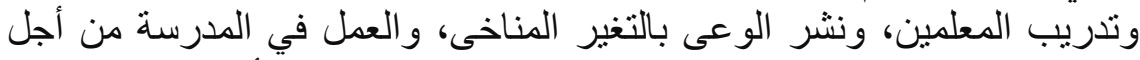
التغير المناخى، ودعم الثر اكات مع المجتمع المحلى (منظمة الأمم المتحدة للتربية المئية

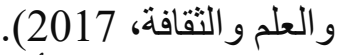

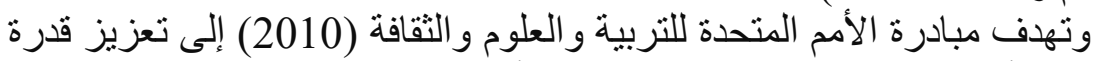

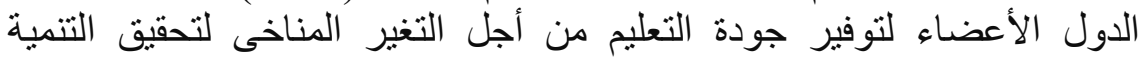

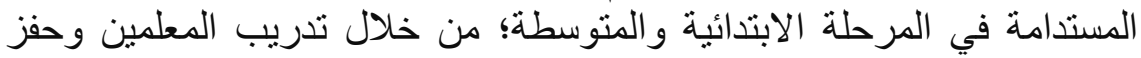

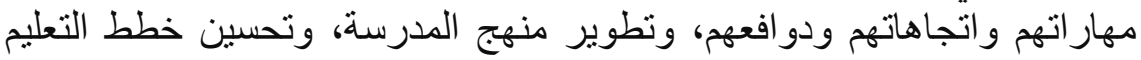

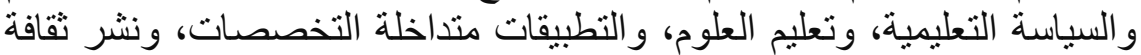
الحد من مخاطر الكوارث الطبيعية، ونشر الوعى بالتغيرات المناخية (United) Nations Educational, Scientific, and Cultural Organization, . (2010

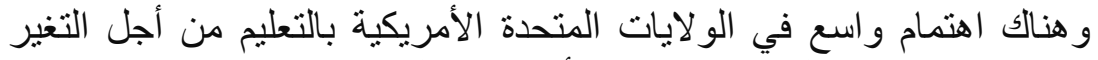

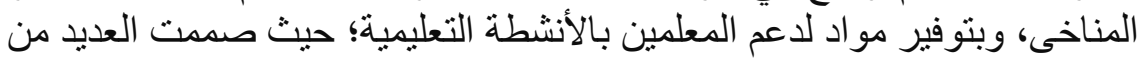

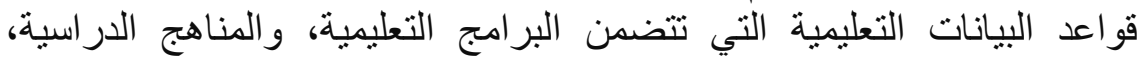

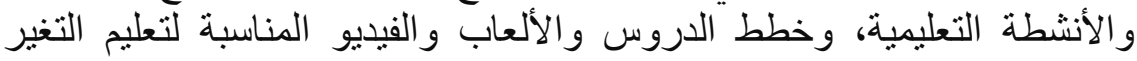

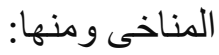

1- برنامج الأطفال في مناخ متغير : منظمة المدخل من أجل تغير المناخ.

Children in a Changing Climate: Climate Change

Education.org.

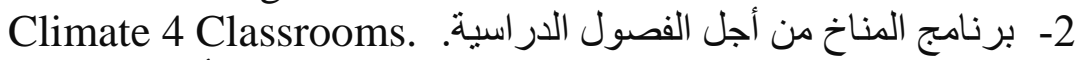
3- مسار تغير المناخ في المدارس البيئية بالولايات المنحدة الأمريكية. Eco-Schools USA Climate Change Pathway. 4- مواجهة تغير المناخ في المستقبل ومصادر الطاقة: الأسبوع الوطنى Facing the Future's Climate Change and للتربية البيئية National Environmental Education Energy Resources:

Week. 


$$
\text { 5- دليل المتعلم لتغير المناخ العالمى. }
$$

A Student's Guide to Global Climate Change.

6- تدريس تغير المناخ. Teaching Climate Change

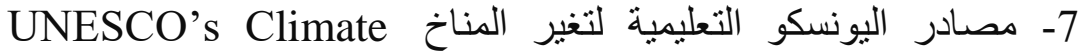

Cordero, Todd, \&) Change Pedagogical Resources

.(Abellera, 2008

وتعد أنشطة STEM التعليمية أحد مجالات تدعيم التعليم في مجال التغير

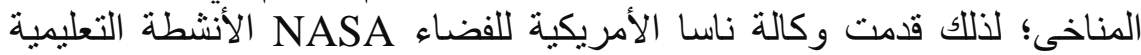

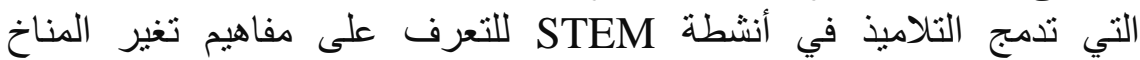

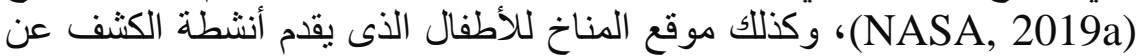
الأدلة التي تسبب ارتفاع درجة الحر ارة العالمية (NASA, 2019b).

كما أنشئت جامعة كاليفورنيا موقع علوم النظام العالمى Global System

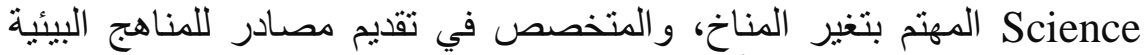

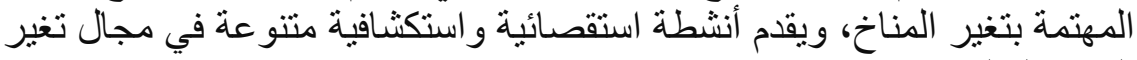

المناخ العالمى (Global System Science, 2019). وقدمت وكالة حماية البيئة الأمريكية مساهمتها في توفير مصادر التعلم التمانم والأنشطة التعليمية المتعلقة بتغير المناخ من خلال دليل للمتعلمين بالمرحلتين

الابتدائية و المتوسطة (Environmental Protection Agency, 2019).

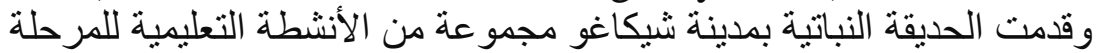
المتوسطة من الصف السابع إلى التاسع؛ بعنوان "تغير المناخ في الفناء الخلفى الخاص بى" Climate Change in My Backyard في إطار مبادرة تغير المناخ التي تطبق منهج وكالة ناسا للفضاء من خلال مجموعة أنشطة تعليمية في أربع وحدات تعليمية (Chicago Botany Garden, 2019).

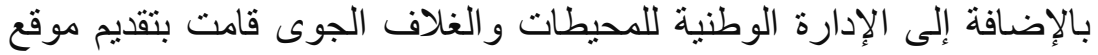

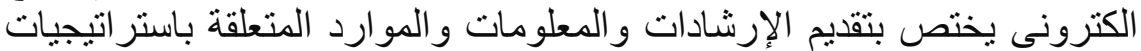
National Oceanic and Atmospheric) تدريس تغير المناخ . (2019 Administration,

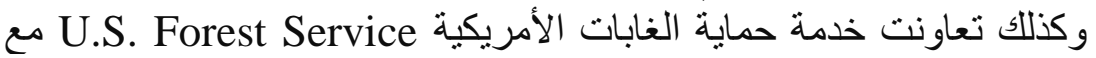

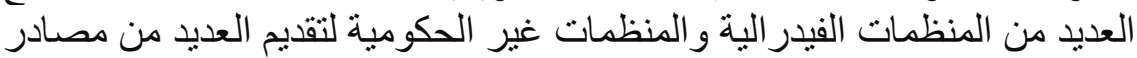

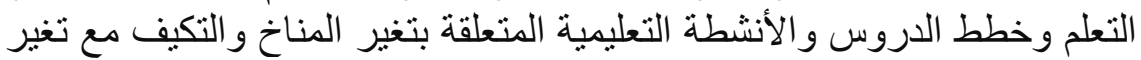
المناخ لجميع الصفوف الدر اسية (U.S. Forest Service, 2019). وقدمت كذللك بالمملكة المتحدة موارد أوكسفام التعليمية حول تغير المناخ Oxfam Education Resources on Climate Change مجموعة مواد تعليمية للمرحلة العمرية من (11-7) سنوات حول تغير المناخ المباخ، OXFAM), والتكيف مع تغير المناخ، واتخاذ سبل العمل لمواجهة تغير المناخ 
و وتتعدد المداخل التربوية المنوط بها تعليم وتتقيف الأفراد بكيفية حماية البيئة،

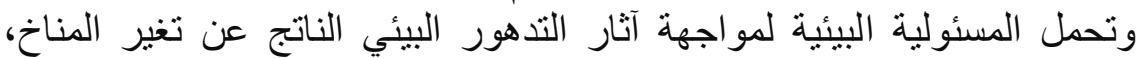

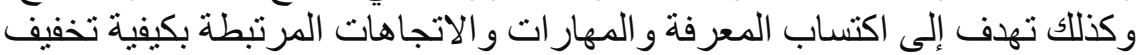

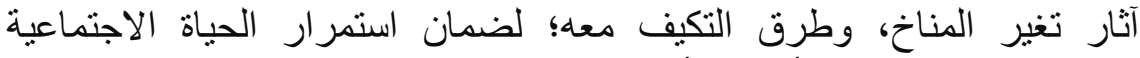
والاقتصادية في مختلف أنحاء الأرض. تلغن

3-1 التربية من أجل مواجهة الكوارث الطبيعية في إطار المدرسة الثاملة Natural Disaster Education in comprehensive School Framework

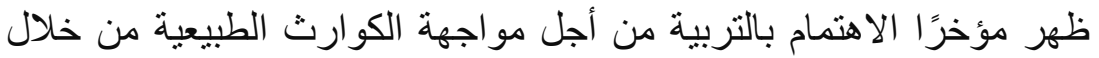

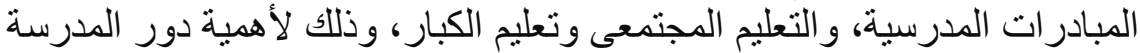

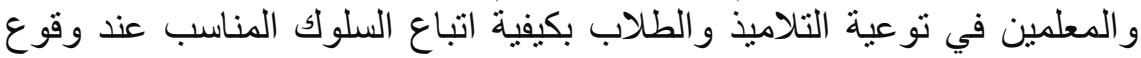

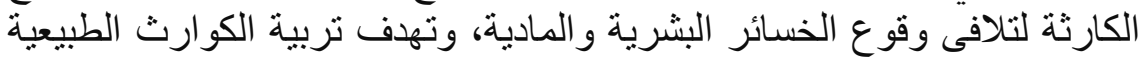

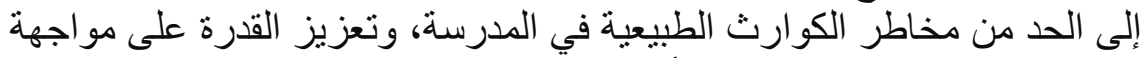
آثنار الكوارث الطبيعية في حياة الأفراد (Preston, 2012).

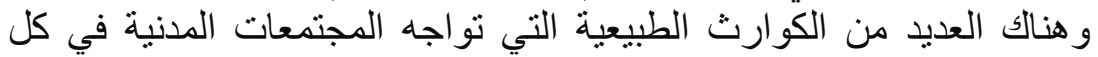

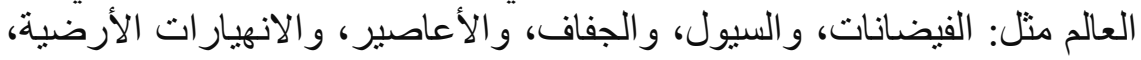

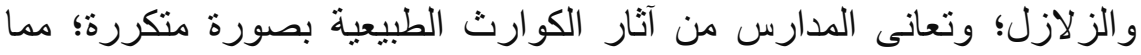

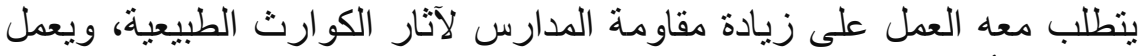

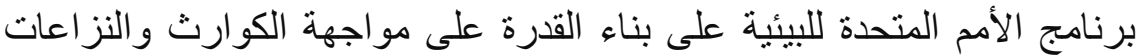

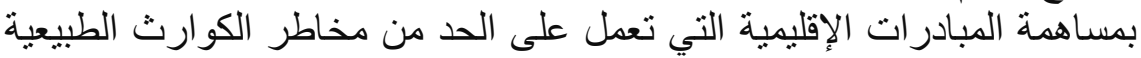

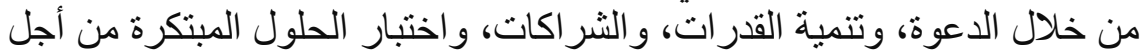

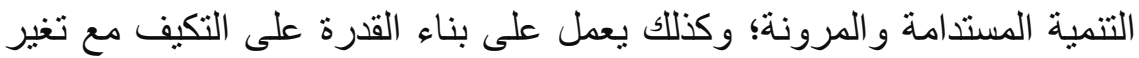
المناخ من خلال النظام الإيكولوجى و إدارة الموارد الطئة الطبيعية (برنامج الأمم

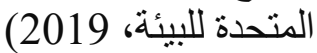

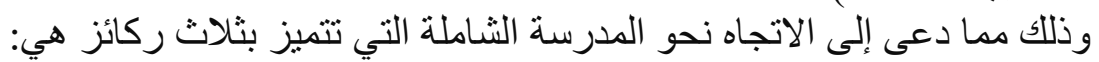

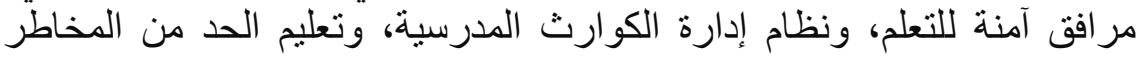

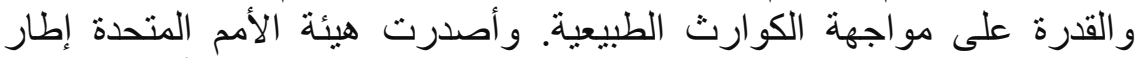

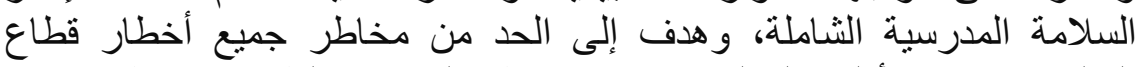

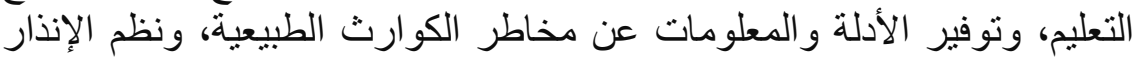

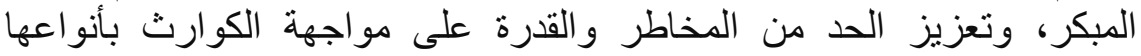

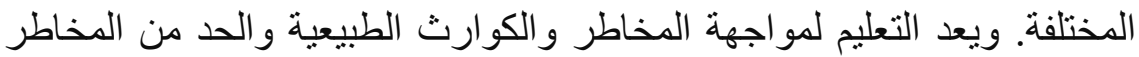

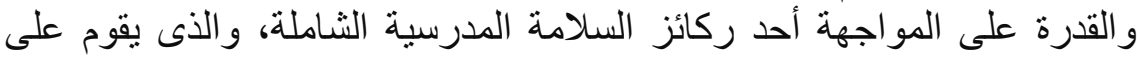

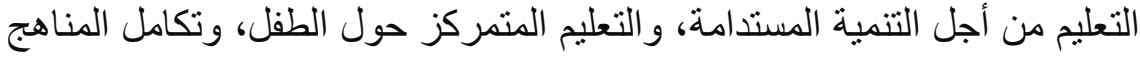

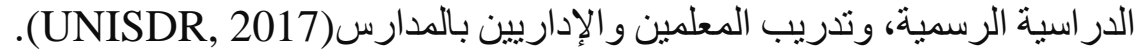
وتتركز جهود المدرسة الثناملة فيما يلى: 


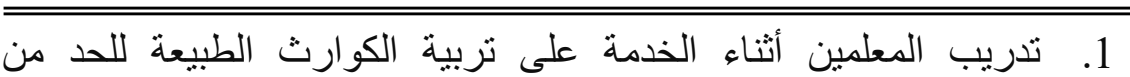
المخاطر ، و القدرة على المو اجهة.

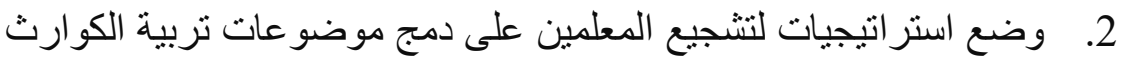

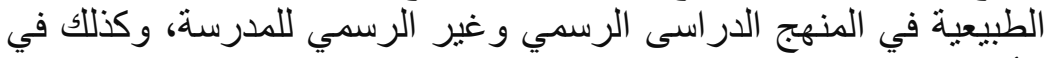
الأنشطة اللاصفية مع البيئة المحلية.

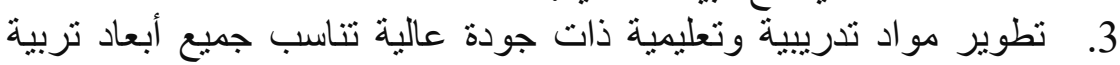
الكو ارث الطبيعية. 4. توفير مبادئ توجيهية للمعلمين لكيفية دمج تربية الكوارث الطبيعية في كافة

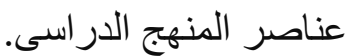

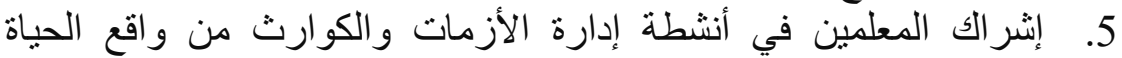

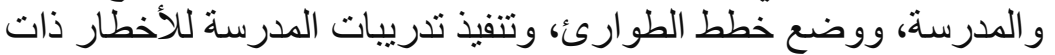

الصلة (UNISDR, 2017).

2- مبادئ تدريب معلمى التعليم قبل الجامعى على التعليم في مجال التغير

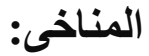

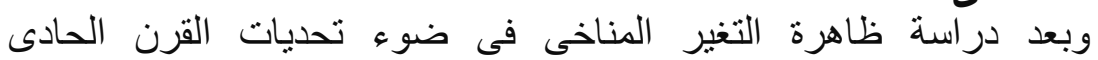

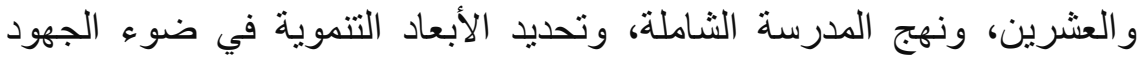

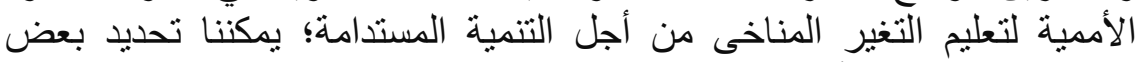

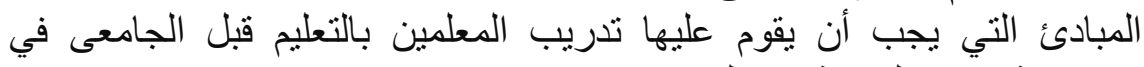
جمهورية مصر العربية كما يلى الئي

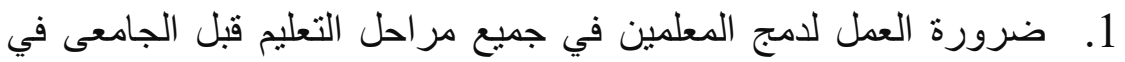

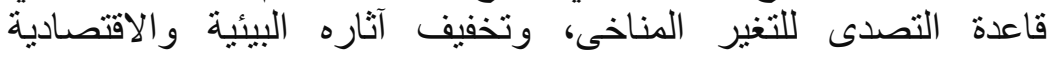

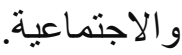

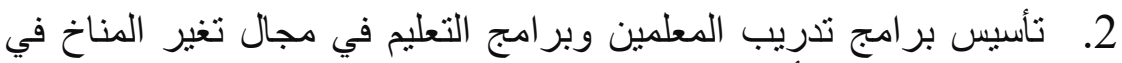
ضوء التربية من أجل التنمية المستدامة.

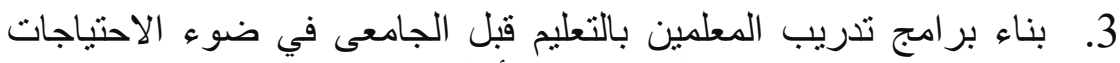

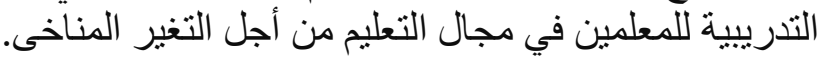

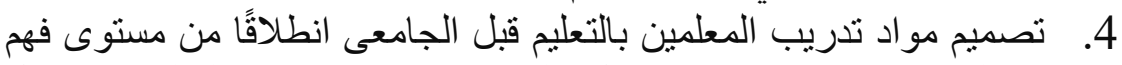
المعلمين للتغير المناخى، و العمل على زيادة دافعينهم نحو التعليم في مجال التهال

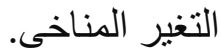
5. تركيز أهداف التعليم في مجال التغير المناخى على تحقيق التكيف مع تغير المناخ؛ وفقًا للظروف التُ التحلية لكل مدرسة.

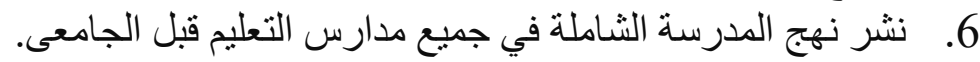

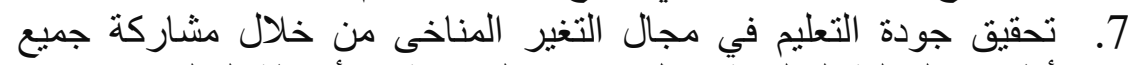
أطر اف العملية التعليمية داخل وخارج المدرسة في أنشطة التعليم. 


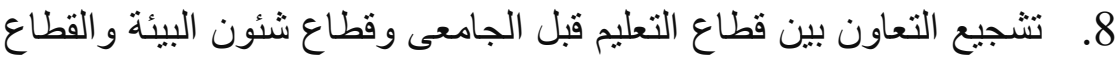

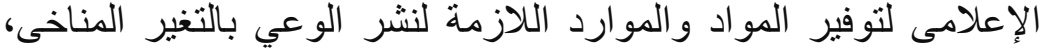
وتحقيق أهداف التعليم في مجال التغير التير المناخى.

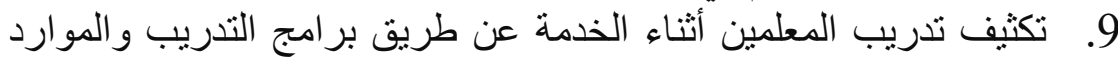

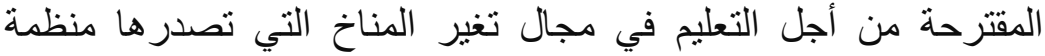

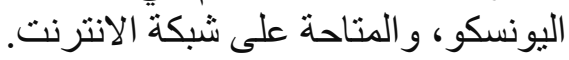

10. توفير المواد و المصادر التعليمية والتكنولوجية اللازمة للتئية للتعليم في مجال التغير المناخى في مدارس التعليم قبل الجامعى. 11. تصميم برامج تدريبية للتعليم في مجال التغير المناخى؛ لتدريب التئي المعلمين بمر احل التعليم قبل الجامعى في جميع مدارس الجمهورية تناسب الظروف الترفي البيئية المحلية لكل مدرسة.

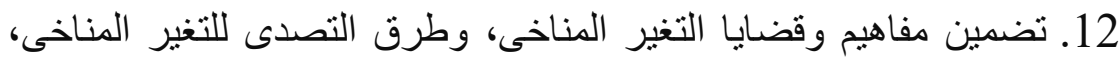

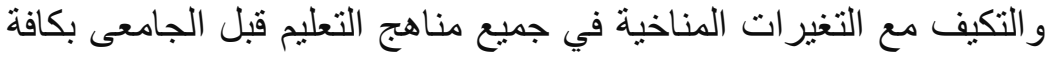
مجالاتها.

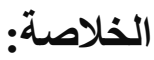

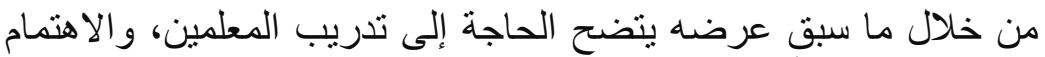

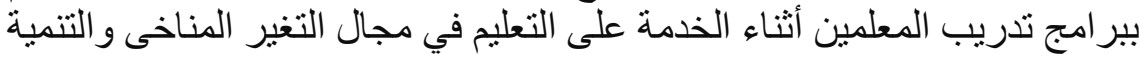

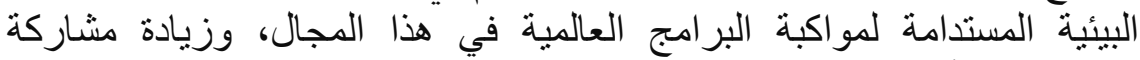

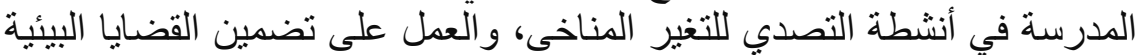

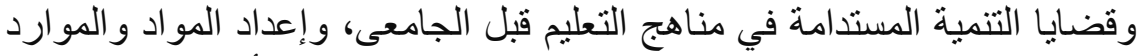

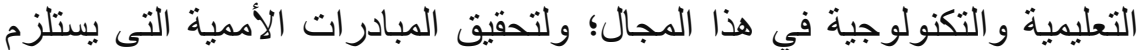

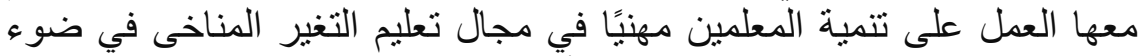
تحديات القرن الحادى و العشرين لتحقيق أهداف التنمية المستدامة.

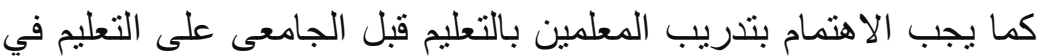

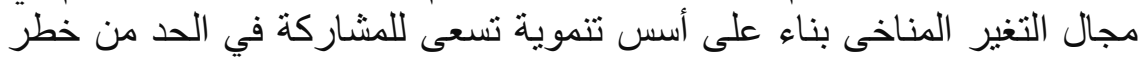

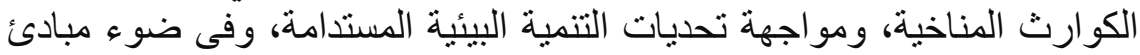

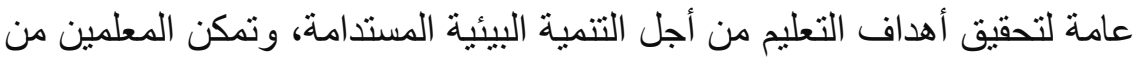

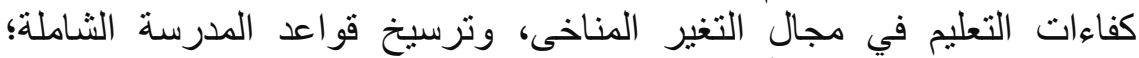

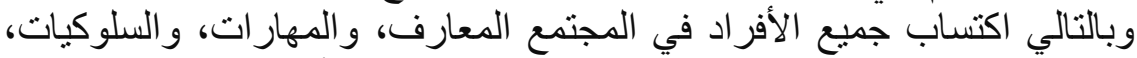

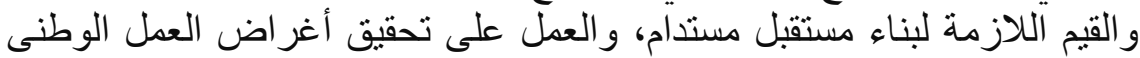

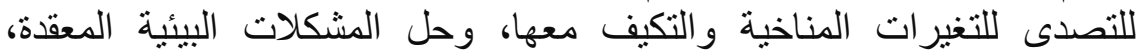

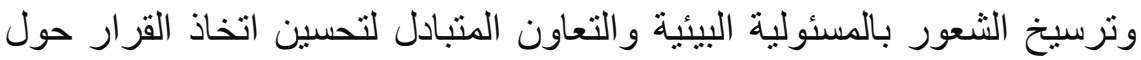
القضايا المجتمعية المستقبلية. 
1- وضع خطة استر اتيجية لتدريب المعلمين بالتعليم قبل الجيل الجامعى على التئ التعليم في

مجال التغير المناخى في ضو أه أهداف التربية من أجل التنمية المستدامئ.

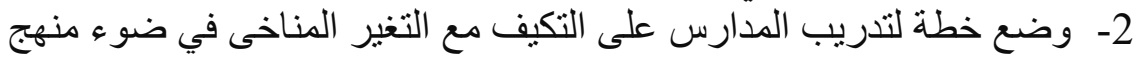

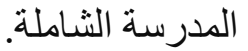

3- تصميم برامج تدريبية للمعلمين في جميع المراحل التعليمية على تتمية

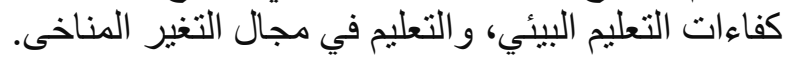

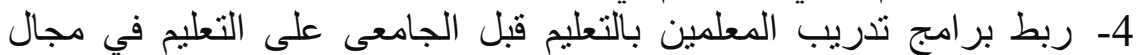

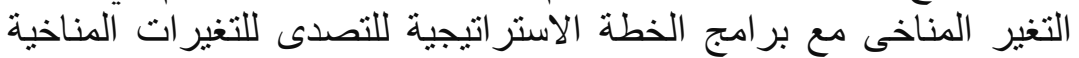
و التكيف معها. 5- إعداد المو اد التعليمية والتكنولوجية اللازمة للتعليم في مجال التغير المناخى التئ و التكيف مع التغير المناخى في جميع المر احل التعليمية.

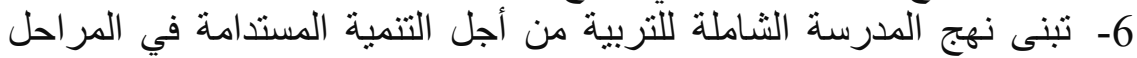
التعليمية المختلفة.

\section{ويمكن تقديم المقترحات التالية:}

دراسة مستوى فهم المعلمين بالتعليم قبل الجامعى للتغير المناخى و وعلاقته

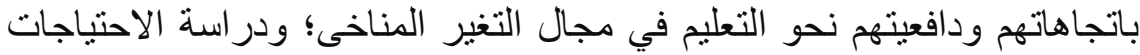

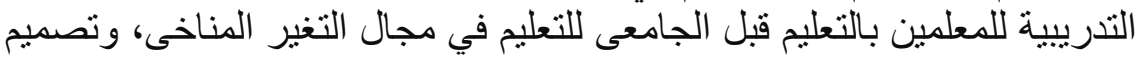

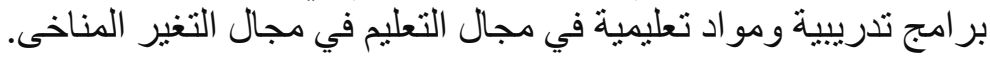

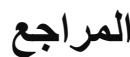

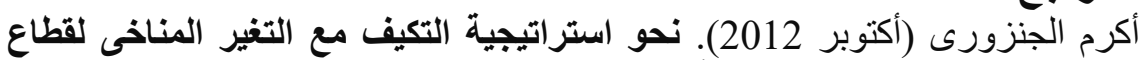

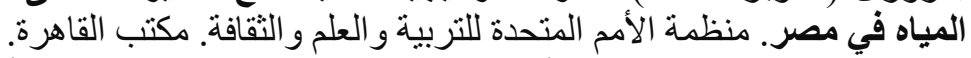
الأمم المتحدة (1992). تقرير مؤتمر الأمم المتحدة المعنى بالبيئة والتنمية. قمة الأرضة.

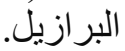

الأمم المتحدة، (1997). تقرير الأمم المتحدة المعنى بالبيئة والتنمية.

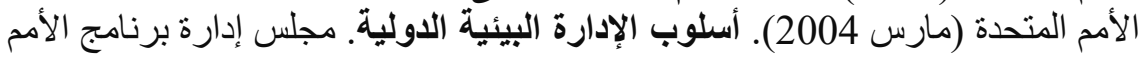

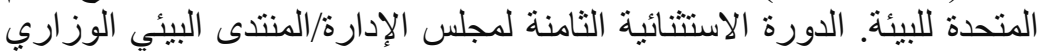
العالمي، جيجو، جمهورية كوريا، 29 - 2015 الآنة آذار.

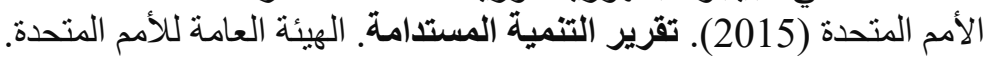
https://www.un.org/ar/climatechange/. الأمم المتحدة (2019) (2015). العمل المناخى.

الأمم المتحدة (2019ب). التعريف بالعمل المناخى. قمة المناخ (2019). https://www.un.org/ar/climatechange/un-climate-summit2019.shtml الجمعية العامة للأمم المتحدة، (2002). التعليم من أجل التنمية المستدامة. عقد الأمم المتحدة للتعليم من أجل التنمية المستدامة (2005-2014). 
الجمعية العامة للأمم المتحدة (2004). الإطار الاستراتيجى المقترح للفترة 2006-

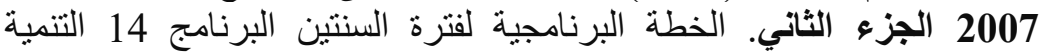
الاقتصادية والاجتماعية في أفريقيا، الدورة التاسعة والخمسون للإنية الجمعية العامة

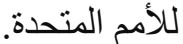

الجمعية العامة للأمم المتحدة (2005). بيان موريثيوس واستراتيجية موريشيوس

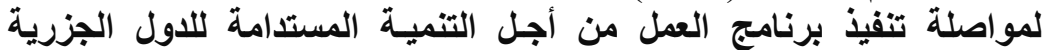

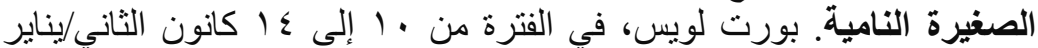
r...

برنامج الإدارة العليا، (2010). التفكير الاستراتيجى. برنامج الدرجة الممتازة. كلية العلوم الإدارية. أكاديمية السادات للعلوم الإدارية.

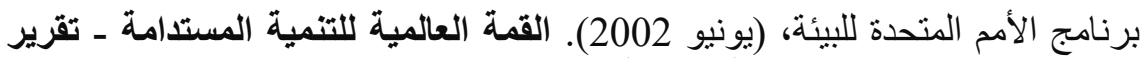

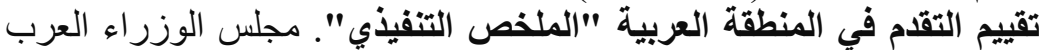
المسئولين عن البيئة. اللجنة الاقتصادية و الاجتماعية لغربى أسيا.

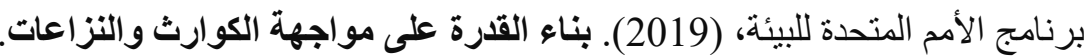
برنامج الأمم المتحدة للبيئة (أبريل (2001). تقريز الإلدارة البيئية الاولية. نيويورك، 18

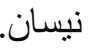
برنامج الأمم المتحدة الإنمائى فى الدول العربية (2012). تقرير تحديات التنمية فى

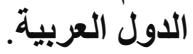
رئاسة مجلس الوزراء (2018). برنامج عمل الحكومة 2021/2020-2019/2018. مصر https://mped.gov.eg/programsandplans.html صالح عزب، (2016). إثكاليات النمذجة الاقتصادية للمناخ. مجلة البحوث الإدارية.

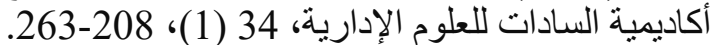

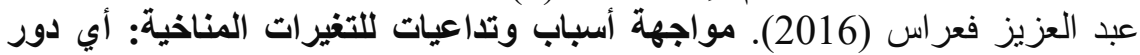

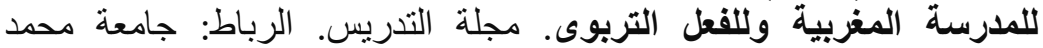

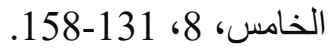
منظمة الأغذية والزر اعة (2015). أهداف التتمية المستدامة. الأمم المتحدة.

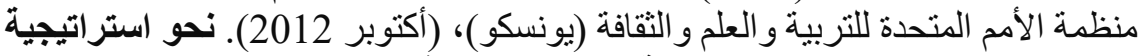
التكيف مع للتغيرات المناخية لقطاع المياه في مصر. مكتبر التبر القاهرة. تقرير جمهورية مصر العربية.MDG Achievement Fund.

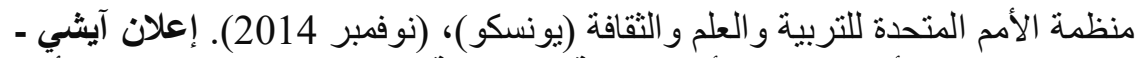
ناغويا بثأن التعليم من أجل التنمية المستدامة. المؤتمر العالمي للتعليم من أجل التل

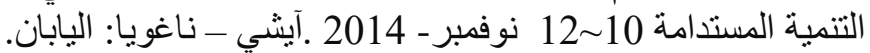
منظمة الأمم المتحدة للتربية والعلم و الثقافة (يونسكو) (2016). تلريب المئية المدارس للتصدى للتغير المناخى. قطاع التربية.

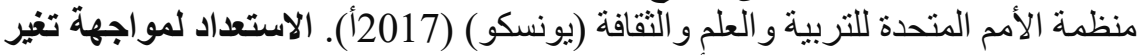
المناخ. دليل المدارس بشأن العمل المناخى. المدارس المنتسبة لليونسكو. 
http://www.unesco.org/new/ar/media-services/single-

view/news/step_by_step_training_to_transform_schools_to_addres s_climat/

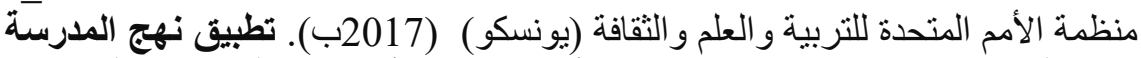

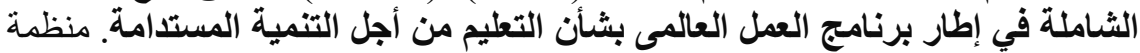
الأمم المتحدة للتربية و العلم و الثقافة. المنظمة العالمية للأرصناد الجوية (2019). https://www.wmo.int/pages/summary/cosponsored_summary_ar.ht $\mathrm{ml}$

ناهد عبد اللطيف محيس، (2011). التغيرات المناخية وانعكاساتها على قطاع الزراعة والغذاء في مصر. مجلة النهضة. جامعة القاهرة: كلية الاقتصاد و العلوم السياسية،

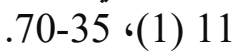

وزارة التخطبط و المتابعة و الإصلاح الإدارى (2014). استر اتيجية التنمية المستدامة. مصر2030. جمهورية مصر العربية.

وزارة التخطيط والمتابعة والإصلاح الإدارى (2015). روئية مصر 2030. استر اتيجة

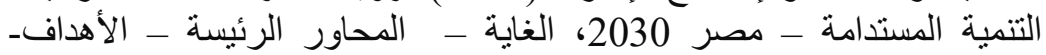
مؤشر ات القياس. وزارة التخطيط و المتابعة و الإصلاح الإدارى. جمهورية مصر الرية

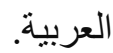

وزارة التخطبط و المتابعة والإصلاح الإدارى، (2018). الخطة متوسطة المدى للتنمية

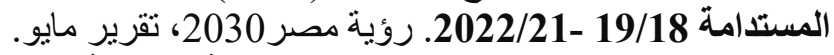

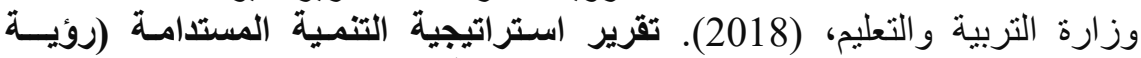

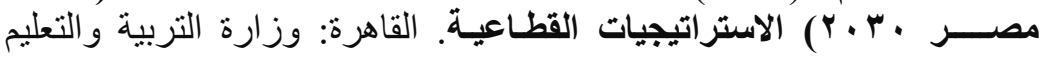

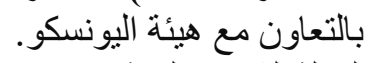

وزارة الدولة لنشئون البيئة (2008). نحو استراتيجية وطنية للتنمية المستدامة. وثثيقة

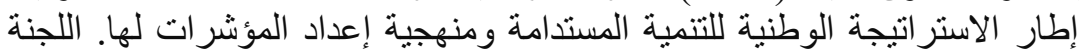

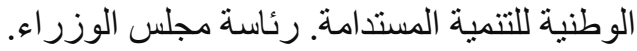

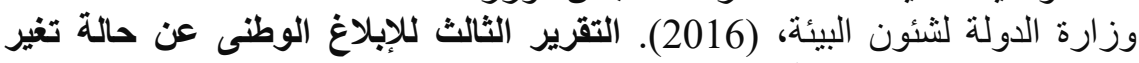
المناخ. جهاز شُئون البيئة.

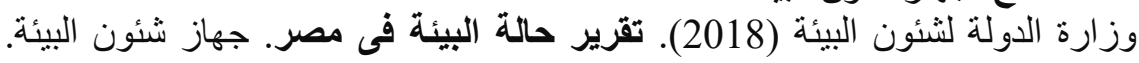

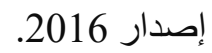

وزارة الموارد المائية والرى (2018). مشروع دعم التكيف مع تغير المناخ. جمهورية مصر العربية.

Anderson, A. (2012). Climate Change Education for Mitigation and Adaptation. Journal of Education for Sustainable Development. SAGE Publications. 191-206, 6 (2).

Australian Academy of Science (2015). The Science of Climate Change. Questions and Answers.

Chicago Botany Garden, (2019). Climate Change in My Backyard. Grade $7-9$ Activity Guide. 
https://www.chicagobotanic.org/nasa/Grades_7-

9_Activity_Guide.

Cordero, E.C., Todd, A.M. \& Abellera, D. (2008). 'Climate Change Education and the Ecological Footprint', Bulletin of the American Meteorological Society, 89 (6): 865-72.

Dawson, V. (Sep 2012). Science Teachers' Perspectives about Climate Change. Teaching Science, 58 (3), 8-13.

Environmental Protection Agency, (2019). A student's Guide to Global Climate Change. USA. https://archive.epa.gov/climatechange/kids/index.html.

EU Science Hub (2018.) Climate Change Mitigation. The European Commission's science and knowledge service.

Foss, A. W.; \& Ko, Y. (2019). Barriers and Opportunities for Climate Change Education: The Case of Dallas-Fort Worth in Texas. Journal of Environmental Education, 50 (3). 145-159.

Global System Science, (2019). Climate Change. http://www.globalsystemsscience.org/studentbooks/cc.

Harris, J. M. (2000). "Basic Principles of Sustainable Development", Global Development and Environment Institute, Working Paper No. 00-04, June.

Herman, B. C.; Feldman, A.; \& Vernaza-Hernandez, V. (Mar 2017). Florida and Puerto Rico Secondary Science Teachers' Knowledge and Teaching of Climate Change Science. International Journal of Science and Mathematics Education, 15 (3), 451-471.

Hestness, E.; McGinnis, J. R.; Breslyn, W.; McDonald, R. C.; \& Mouza, C. (2017). Examining Science Educators' Perspectives on Learning Progressions in a Climate Change Education Professional Development Program. Journal of Science Teacher Education, 28 (3). 250-274.

Khan, I. (2015). Science: not just for Scientists, The Guardian. Retrieved from https://www. theguardian.com/science/politicalscience/2015/dec/01/scienc e-not-just-for-scientists (accessed 8/8/2019).

Kunkle, K. A.; \& Monroe, M. C. (2019) Cultural Cognition and Climate Change Education in the U.S.: Why Consensus Is Not Enough. Environmental Education Research, 25 (5), 633-655.

Liu, S.; Roehrig, G.; Bhattacharya, D.; \& Varma, K. (Sum 2015). In-Service Teachers' Attitudes, Knowledge and Classroom 
Teaching of Global Climate Change. Science Educator, 24 (1), 12-22.

McGinnis, J. R.; McDonald, C.; Hestness, E.; \& Breslyn, W. (2016). An Investigation of Science Educators' View of Roles and Responsibilities for Climate Change Education. Science Education International, 27 (2), 179-193.

McNeal, P.; Petcovic, H.; \& Reeves, P. (2017). What Is Motivating Middle-School Science Teachers to Teach Climate Change? International Journal of Science Education, 39 (8), 10691088.

Monroe, M. C.; Plate, R. R.; Oxarart, A.; Bowers, A.; \& Chaves, W. A. (2019). Identifying Effective Climate Change Education Strategies: A Systematic Review of the Research. Environmental Education Research, 25 (6), 791-812.

Munich Re, (2010): Natural Catastrophes 2009. Analyses, assessments, positions. TOPICS GE. Retrieved from https://www.munichre.com/en/reinsurance/business/nonlife/n atcatservice/index.html.

National Institute for Environmental Studies, (2017). What is climate change adaptation? Japan.

National Oceanic and Atmospheric Administration, (2019). Teaching Climate. https://www.climate.gov/teaching.

Nasa (2019a). NASA STEM Engagement. https://www.nasa.gov/stem/.

Nasa (2019b). Climate Kids. https://climatekids.nasa.gov/climatechange-evidence/.

OXFAM, (2019). Oxfam Education Resources on Climate Change. https://www.oxfam.org.uk/education/resources/climatechallenge-7-11.

Preston, J. (2012). Disaster Education. Race, Equity, and Pedagogy. Netherlands: Sense Publishers.

Santiago, O. (July 2001).Vulnerability and Adaptation to Climate Change: Concepts, Issues, Assessment Methods. The Climate Change Knowledge Network. www.cckn.net.

Seow, T.; \& Ho, Li-Ching (2016). Singapore Teachers' Beliefs about the Purpose of Climate Change Education and Student Readiness to Handle Controversy. International Research in Geographical and Environmental Education, 25 (4), 358-371.

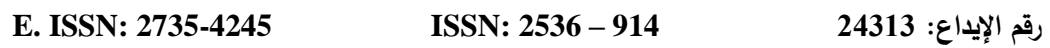

المجلة معرفة علي دوريات بنك المعرفة المصرى، و Edu Search دار المنظومة
} 
المجلة المصرية للتربية العلمية المجلد الثالث والعشرون العدد الساد أكتوبر 2020م

Sustainable Development Goal-13, (2015). http://www.un.org/sustainabledevelopment/ar/climatechange/

U.S. Forest Service, (2019). Climate Change Live. https://climatechangelive.org/index.php?pid=180.

UNESCO (2013). Climate Change in the Classroom - UNESCO Course for Secondary Teachers on Climate Change Education for Sustainable Development. http://www.unesco.org/new/en/ccesd.

UNISDR (2017). Comprehensive School Safety Framework. United Nation.

United Nation Institute for Training and Research, (2013). Integrating Climate Change in Education at Primary and Secondary Level. The One UN Climate Change Learning Partnership (UN CC:Learn).

United Nations Educational, Scientific, and Cultural Organization (2010). The UNESCO Climate Change Initiative. Climate Change Education for Sustainable Development. 